\title{
Prognostic Factors of Papillary and Follicular Carcinomas in Japan Based on Data of Kuma Hospital
}

\author{
Yasuhiro Ito and Akira Miyauchi \\ Department of Surgery, Kuma Hospital, 8-2-35, Shimoyamate-dori, Chuo-ku, Kobe 650-0011, Japan \\ Correspondence should be addressed to Yasuhiro Ito, ito01@kuma-h.or.jp \\ Received 6 April 2011; Accepted 28 July 2011 \\ Academic Editor: Nikola Besic
}

Copyright ( $) 2012$ Y. Ito and A. Miyauchi. This is an open access article distributed under the Creative Commons Attribution License, which permits unrestricted use, distribution, and reproduction in any medium, provided the original work is properly cited.

\begin{abstract}
There are some important prognostic factors for papillary thyroid carcinoma (PTC) and follicular thyroid carcinoma (FTC). In this paper, clinicopathological features significantly affecting patient prognosis are described based on our data as well as others. Distant metastasis at diagnosis is the most important prognostic factor for both PTC and FTC. Other than that, preoperative and intraoperative findings are important to evaluate the biological behavior of PTC. Extrathyroid extension, large lymph-node metastasis, and extranodal tumor extension that can be evaluated preoperatively or intraoperatively are significant prognostic factors for PTC patients. In contrast, pathological findings are important not only for diagnosis of FTC, but also for the evaluation of its biological character. Grade of invasiveness (minimally or widely invasive) and degree of differentiation (well differentiated or including a poorly differentiated component) greatly affect the prognosis of FTC patients.
\end{abstract}

\section{Introduction}

There are two histological types of thyroid carcinoma arising from follicular cells, which are papillary carcinoma (PTC) and follicular carcinoma (FTC). These two histological types are also called differentiated carcinoma (DTC) and analyzed as a single group for clinical studies investigating prognostic factors and prognosis of patients. However, biological behaviors of these two carcinomas significantly differ. PTC frequently metastasizes to the regional lymph nodes and can show a high incidence of significant extrathyroid extension to adjacent organs. In contrast, it is comparably rare for FTC to show these events, but FTC more frequently metastasizes to distant organs such as the lung, bone, and brain than PTC. Therefore, analyses of prognostic factors and prognosis of patients should be performed separately for PTC and FTC. Generally, PTC and FTC are indolent diseases and show good prognoses of patients, but when the lesion dedifferentiates, becoming undifferentiated carcinoma (anaplastic carcinoma), the prognosis of patients turned to be extremely poor. The mechanism of dedifferentiation remains unknown although the $p 53$ gene mutation is frequently observed in UC [1].
In the 1980s, a pathological entity of poorly differentiated carcinoma (PDC) was proposed by Sakamoto et al. [2] and Carcangiu et al. [3]. PDC implies thyroid carcinoma of intermediate type between DTC and UC. It was adopted as an independent histopathological category from PTC and FTC in the WHO classification [4]. However, as described below, there are three kinds of diagnostic criteria for PDC defined in General Rules for the Description of Thyroid Cancer established by Japanese Society of Thyroid Surgeons (JSTS) [5], in WHO classification [4], and in the Turin proposal [6], which generates confusion among pathologists and clinical physicians.

In this paper, we present the prognosis and prognostic value of PTC and FTC together with PDC based on data from Kuma Hospital as well as search results of studies from other institutes. Since the traditional Japanese diet is iodinerich, the results may somewhat differ from those in Western countries.

\section{Prognostic Factors of PTC}

To date, several prognostic factors have been identified for PTC. These factors can be divided into 4 categories, 
backgrounds of patients, factors based on preoperative, and intraoperative and postoperative evaluations. Backgrounds of patients include age, gender, and family history. Preoperative evaluation is mainly performed by imaging studies. Of these, ultrasonography is the most useful tool to detect and evaluate primary lesions [7] and regional lymph node metastasis except for metastasis to the mediastinal and retropharyngeal nodes. In order to diagnose metastasis to the upper mediastinal node and retropharyngeal node, other imaging studies such as CT scan, MRI, and PETCT are useful. Ultrasonography cannot only detect thyroid nodules, but also qualitatively diagnose these nodes based on the findings. Our institution diagnoses whether thyroid nodules are malignant or benign based on our own ultrasonographic grading system [7]. In association with ultrasonography-guided fine-needle aspiration biopsy (FNAB), minute thyroid carcinoma, especially PTC, can be diagnosed. Furthermore, size, location, and multiplicity of primary lesions can be evaluated on ultrasonography. Lymph node metastasis can also be diagnosed based on ultrasonographic criteria. Among the systems available, the criteria proposed by Antonelli et al. [8] are representative: maximal diameter $>1 \mathrm{~cm}$, clear hypoechoic pattern, and rounded (shorter/longer diameter ratio $>0.7$ ) or bulging shape with increased anteroposterior diameter. These criteria are almost the same as those used in our institution except for maximal diameter $>1 \mathrm{~cm}$. Ultrasonography-guided FNAB and thyroglobulin measurement on wash-out of needles used for FNAB [9] could be a great help to diagnose whether the node is metastatic or reactive. Especially, it is useful to diagnose whether clinical node metastasis in the lateral compartment (level II-IV) is present and to decide whether therapeutic modified radical neck dissection (MND) should be performed.

Intraoperative evaluation is based on findings during surgery, including extrathyroid extension and extranodal tumor extension to adjacent organs. The degree of extension, that is, to where and how the tumor extends, significantly affects the prognosis of patients as described later.

Postoperative evaluation includes findings based on pathological and molecular examinations. There are various histological types in PTC, most of which are diagnosed on pathological examination. Molecular examination includes, for example, $B R A F$ mutation analysis.

\subsection{Prognostic Factors Related to Patient Backgrounds}

2.1.1. Patient Age. Patient age is an important background factor for predicting prognoses. Several classification systems have adopted age as a prominent factor in deciding whether carcinoma should be considered high risk. For example, AMES set the cutoff age at 41 for males and 51 for females to discriminate between high-risk and low-risk patients [10]. UICC TNM classification [11] and CIH classification [12] set the cutoff age at 45 years and 50 years, respectively. MACIS is a scoring system that also includes patient age as a very significant factor [13]. In our setting series, the cutoff age at 45 years affected the cause-specific survival (CSS) of patients to some extent, but its prognostic impact for diseasefree survival (DFS) was weak [14] (Figures 1(a) and 1(b)). Currently, we set the cutoff age at 55 years, because this most significantly reflected patient DFS and CSS in our series (Figures $1(\mathrm{c})$ and $1(\mathrm{~d})$ ). On multivariate study, age at 55 years or older was the most significant prognostic factor for CSS, except for distant metastasis at surgery [15].

2.1.2. Gender. Previous studies showed discrepant findings regarding the prognostic value of gender [16-18]. In our analysis of 6015 PTC patients, male gender was an independent but moderate prognostic factor for DFS and CSS [15].

As indicated above, age and gender each independently affect patient prognosis. However, our recent data indicate that the significance of other prognostic factors varied according to patient age and gender when analyzed in four subsets of patients; older female, older male, younger female and younger male. This issue will later be described briefly as an addendum.

2.1.3. Family History. PTC and FTC are generally considered sporadic with the exception that these are lesions also associated with rare inherited diseases such as familial adenomatous polyposis, Gardner syndrome, and Cowden disease $[19,20]$. However, case reports of DTC in monozygotic twins and in a mother and son were published in 1955 and 1975, respectively, [21,22]. More recently, population studies showed that the risk of DTC was elevated in individuals with a first-degree relative having DTC $[23,24]$. Although the genes that cause these lesions have not been identified, a definition of familial nonmedullary thyroid carcinoma (FNMTC) has been established as patients with DTC having one or more affected persons among their first-degree of relatives [25]. It remains controversial whether FNMTC shows a different prognosis from sporadic DTC [26-30]. In Japan, there are two studies investigating this issue in a large series of patients [31, 32]. One study showed that FNMTC was more likely to recur, but its CSS did not differ from that of sporadic DTC [31]. The other study demonstrated that DFS and CSS of familial PTC did not differ from sporadic PTC [32] (Figures 2(a) and 2(b)). Interestingly, the incidences of FNMTC in the two studies were similar at about $5 \%$. Currently, we have no evidence that familial PTC shows a significantly worse DFS than sporadic PTC or that the therapeutic strategy should be changed. However, familial PTC is more likely to be multiple, and recurrence rate to the remnant thyroid, if total thyroidectomy is not performed, is higher than that in patients with sporadic lesions (5\% versus $1 \%$ ) [32]. Therefore, total thyroidectomy is recommended for familial PTC patients regardless of carcinoma stage.

\subsection{Prognostic Factors Predominantly Based on Preoperative Evaluation}

2.2.1. Tumor Size. Tumor size was adopted as a factor discriminating high-risk patients from others in various classification systems such as UICC classification [11], 


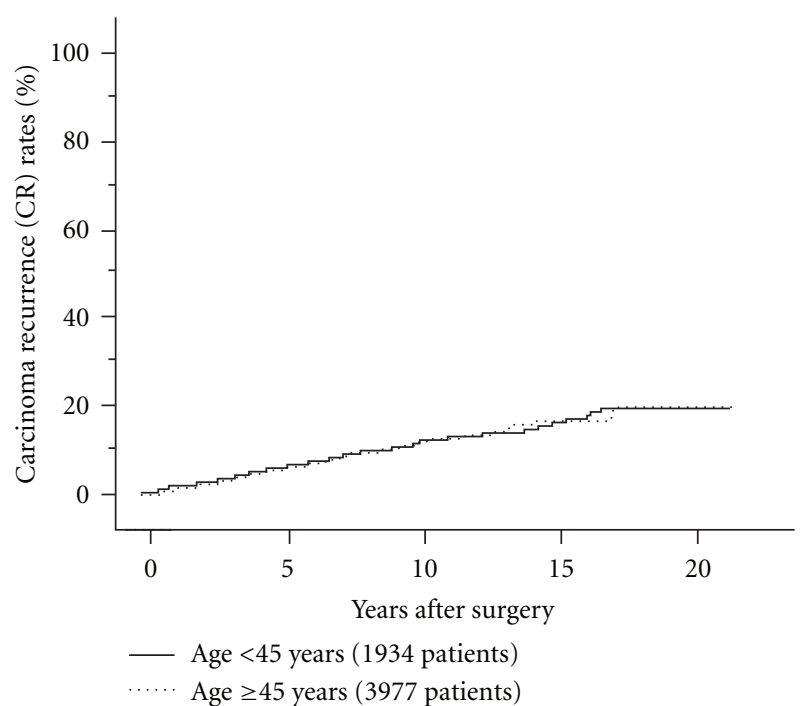

(a)

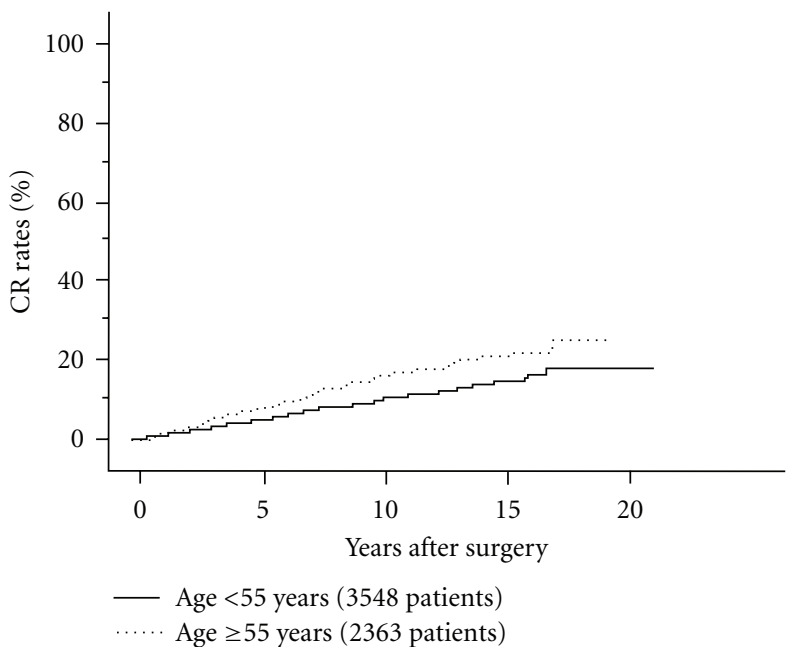

(c)

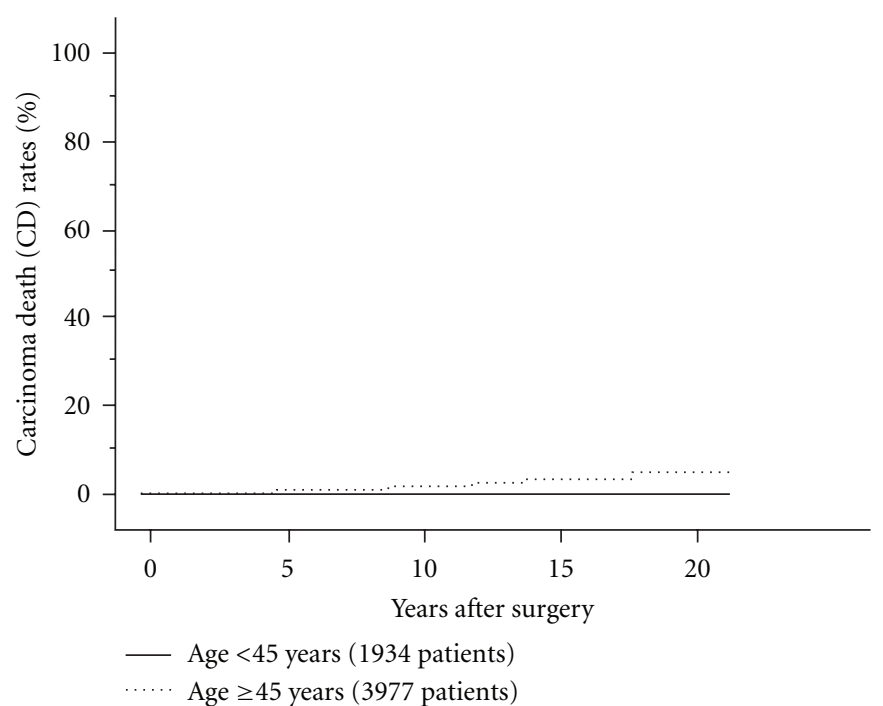

(b)

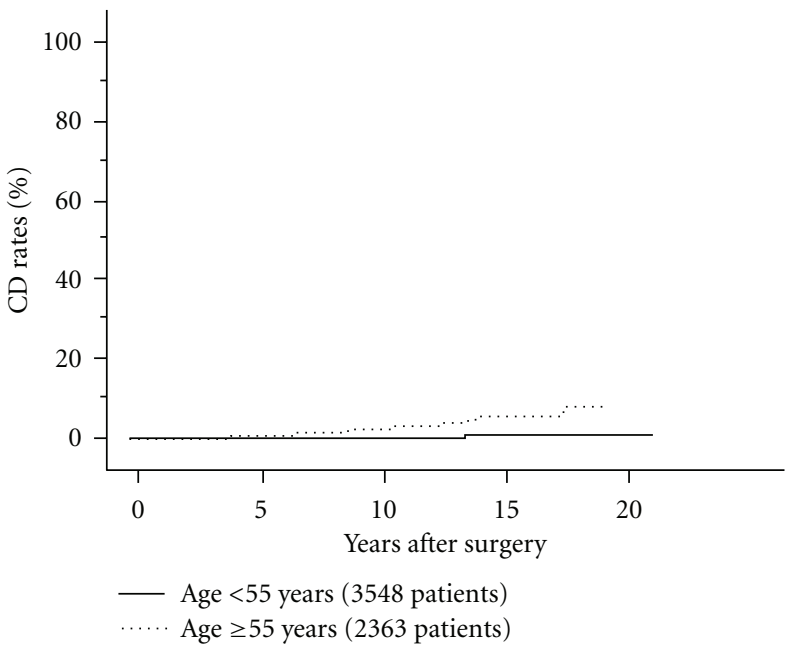

(d)

Figure 1: (a) Carcinoma recurrence (CR) rate of PTC patients aged 45 years or older and those younger than 45 years. (b) Carcinoma death (CD) rates of PTC patients aged 45 years or older and those younger than 45 years. (c) CR rates of PTC patients aged 55 years or older and those younger than 45 years. (d) CD rates of PTC patients aged 55 years or older and those younger than 45 years.

MACIS scoring system [13], and AMES [10]. In UICC TNM classification, there are two cutoffs, $2 \mathrm{~cm}$ and $4 \mathrm{~cm}$ (T1 for $2 \mathrm{~cm}$ or less, T2 for $2.1-4 \mathrm{~cm}$, and T3 for larger than $4 \mathrm{~cm}$ ) [11]. In AMES, $5 \mathrm{~cm}$ is a cutoff between high-risk and lowrisk patients [10].

Recently, an observation trial for PTC measuring $1 \mathrm{~cm}$ or less (microcarcinoma) without any high-risk features such as clinical lymph node and/or distant metastasis has been performed in some institutions in Japan [33-37]. In our data, only about $7 \%$ of low-risk microcarcinoma significantly enlarged during followup once or twice per year for 5 years, and none of these patients showed recurrence or died of carcinoma after surgery at the appearance of progression signs such as tumor enlargement and newly detected lymph node metastasis. In Japan, therefore, cutoff at $1 \mathrm{~cm}$ was considered important and General Rules for the Description of Thyroid Cancer established by JSTS further divided T1 into two categories, T1a (1 cm or less) and T1b $(1.1-2 \mathrm{~cm})$ [5]. Previous autopsy studies demonstrated that small thyroid carcinoma was detected with a significantly high incidence [38-40]. Furthermore, thyroid carcinomas were detected in $3.5 \%$ of otherwise healthy Japanese women aged 30 years or older using ultrasonography and ultrasonographyguided FNAB [41]. Thus, it is suggested that most small thyroid carcinomas remain latent and do not or only very slowly grow. The successful results of an observation trial of microcarcinoma indicated that the above should, therefore, be reasonable. 


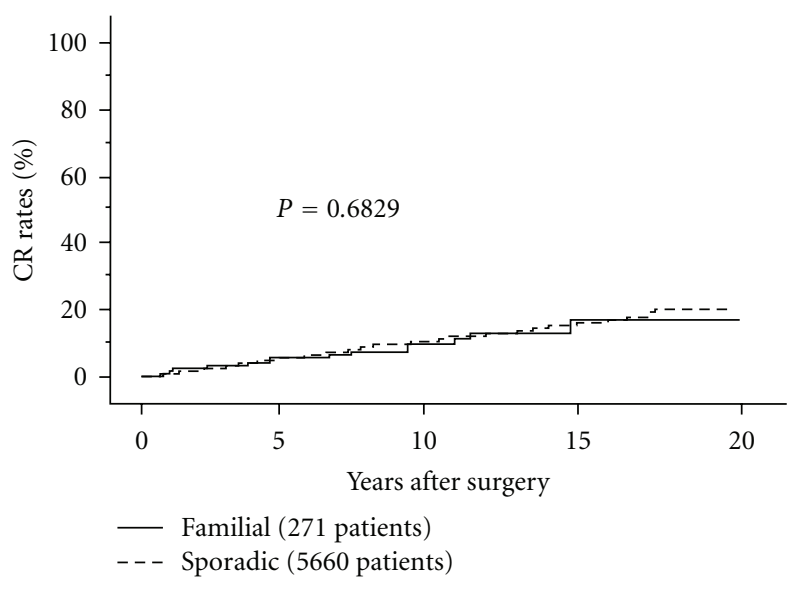

(a)

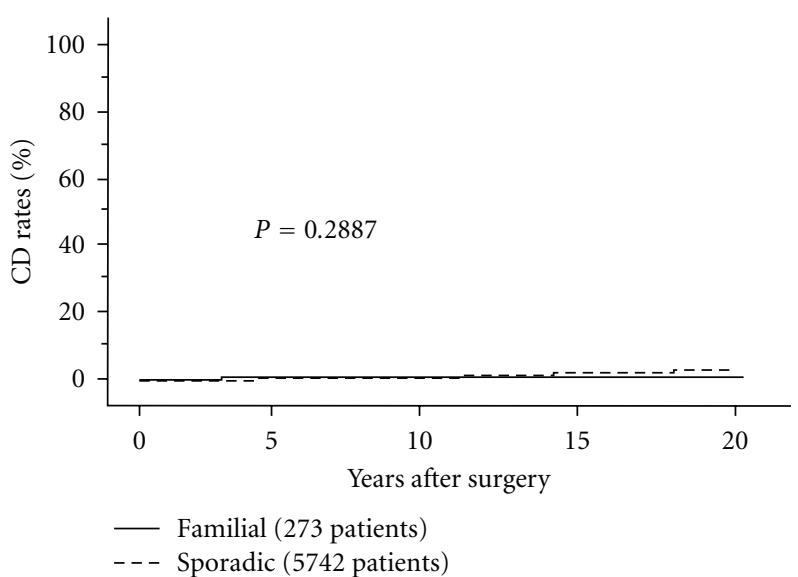

(b)

FIgURE 2: (a) CR rates of familial and sporadic PTC patients.

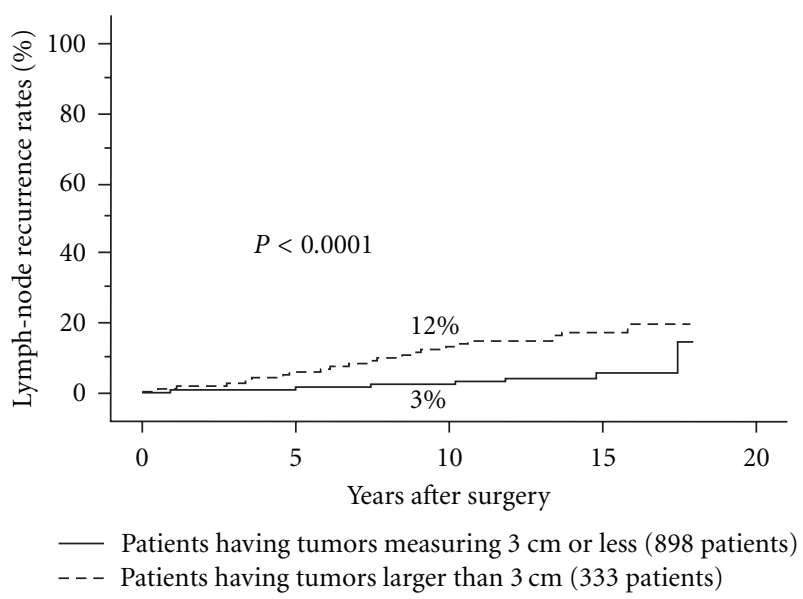

FIGURE 3: Lymph-node recurrence rates of PTC patients having tumors larger than $3 \mathrm{~cm}$ and those having tumors measuring $3 \mathrm{~cm}$ or less.

In contrast, in our data based on a series of patients treated in our institution, tumor size larger than $4 \mathrm{~cm}$ significantly affected DFS and CSS of PTC patients on multivariate analysis [15]. Therefore, careful and extensive surgery and postoperative followup are recommended for PTC patients larger than $4 \mathrm{~cm}$ even though there are no other high-risk features. Furthermore, 10-year lymph-node recurrence rates of N0 or N1a PTC patients having tumors larger than $3 \mathrm{~cm}$ were higher at $13 \%$ than that of those measuring $3 \mathrm{~cm}$ or less, which was $3 \%$ even though patients underwent central node dissection and prophylactic MND [42] (Figure 3). If prophylactic MND were not performed, lymph-node recurrence rate would be even higher for N0 or N1a PTC larger than $3 \mathrm{~cm}$. Based on these data, our institution performs prophylactic MND for N0 or N1a PTC with a tumor larger than $3 \mathrm{~cm}$. Sugitani et al. also showed that PTC larger than $4 \mathrm{~cm}$ should be indicated for prophylactic MND [43].
2.2.2. Multiplicity of Primary Lesions. PTC is frequently multiple. We previously showed that lateral node metastasis is more frequently detected in multiple microcarcinomas than in solitary microcarcinomas [34]. It is, therefore, suggested that multiplicity reflects the aggressive behavior of PTC to some extent. However, in our study analyzing over 6000 patients with PTC, multiplicity was not an independent prognostic factor on multivariate analysis [14].

There is a limitation in diagnosing multiplicity of PTC on ultrasonography. Our data on microcarcinoma demonstrated that the diagnostic accuracies of ultrasonography for multiplicity were $53 \%$ for sensitivity and $85 \%$ for specificity [14]. This indicates that preoperative evaluation on ultrasonography often overlooks multiplicity of carcinoma, which is one of the reasons for almost routine recommendation of total thyroidectomy for PTC patients. However, our institution generally performs hemithyroidectomy for patients with PTC measuring $2 \mathrm{~cm}$ or smaller (T1 in UICC TNM classification) diagnosed as solitary on ultrasonography, unless they have clinical lymph node or distant metastasis or family histories. The 10-year carcinoma recurrence rate was only $5 \%$ for these patients (Figure 4(a)). The risk of recurrence to the remnant thyroid was only $1 \%$ for patients who underwent limited thyroidectomy, and, if this risk is ignored, the extent of thyroidectomy did not affect patient prognosis (Figure 4(b)) [44]. Even though tiny PTC lesions remain undissected, these lesions are generally harmless for such lowrisk patients. Therefore, we currently conclude that total thyroidectomy is not mandatory for solitary T1N0M0 patients.

2.2.3. Clinical Lymph Node Metastasis (N). Lymph node metastasis is a very common event and recognized as one of the most important prognostic factors. However, prominent classification systems such as AMES [10] and MACIS [13] do not adopt lymph-node metastasis as a prognostic factor. This may be possibly because these systems were based on a series of patients who underwent surgery before the establishment of routine ultrasonography as a preoperative imaging study for accurate evaluation of lymph-node metastasis. 


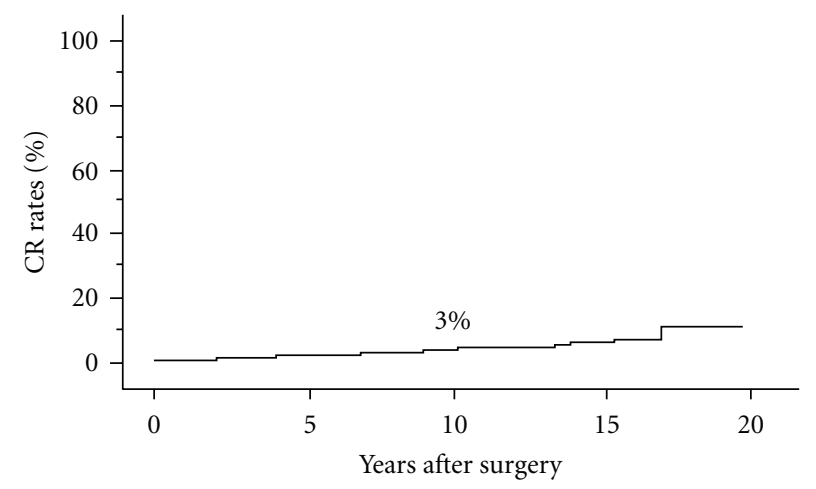

(a)

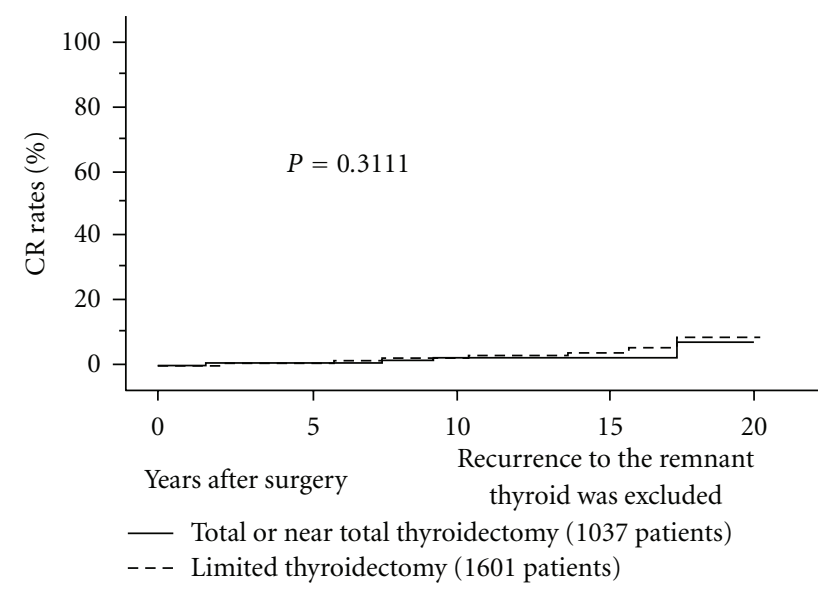

(b)

Figure 4: (a) CR rates of solitary T1N0M0 PTC patients. (b) CR rates of solitary T1N0M0 PTC patients who underwent total or near total thyroidectomy and those who underwent limited thyroidectomy excluding recurrence to the remnant thyroid. Recurrence to the remnant thyroid is ignored.

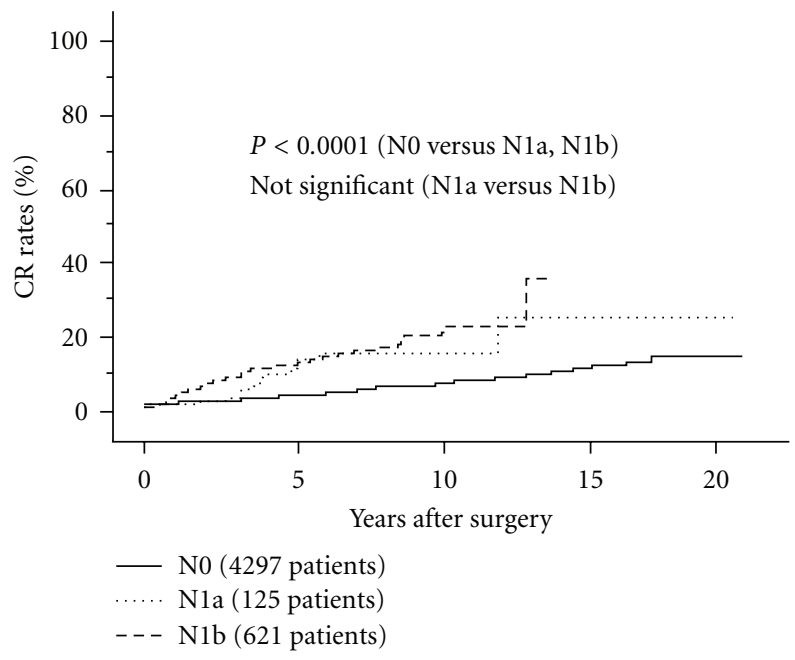

(a)

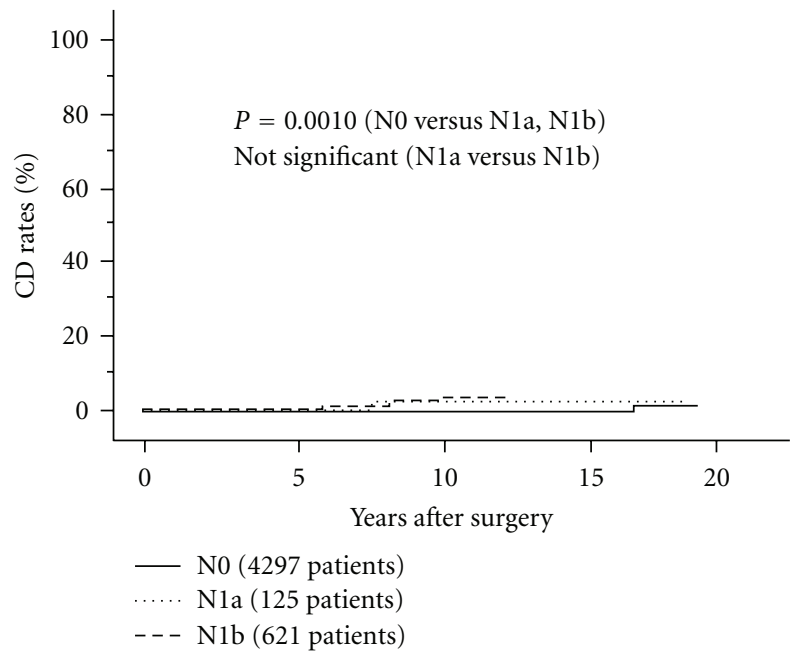

(b)

FIgURE 5: CR rates of N0, N1a, and N1b PTC patients without extrathyroid extension.

At present, lymph-node metastasis can be preoperatively evaluated on imaging studies, and, as indicated above, ultrasonography is the most useful tool for this purpose. Node metastasis detected on preoperative imaging studies is called clinical lymph node metastasis $(\mathrm{N})$, which is discussed in this section. Similar to multiplicity, ultrasonography often overlooks lymph-node metastasis, which can only be diagnosed on postoperative pathological examination in a large number of cases, as described later.

Evaluation of clinical node metastasis is very important, and it was divided into two categories in UICC TNM classification [11]: N1a, central node metastasis and N1b, metastasis to the lateral or mediastinal compartment. In this classification, N1b is upgraded compared to N1a and N1b patients are further upstaged if they are aged 45 years or older.
Indeed, $\mathrm{N}$ has an important prognostic impact. We previously showed that N1b was an independent prognostic factor affecting both DFS and CSS [33, 45-49]. However, more recently, we also demonstrated that in the subset of patients without significant extrathyroid extension, prognosis of patients with N1b did not much differ from that of N1a patients although it was significantly worse than N0 patients [50] (Figures 5(a) and 5(b)). Therefore, it remains unclear whether it is appropriate to upgrade $\mathrm{N} 1 \mathrm{~b}$ compared with N1a. Importantly, CIH classification adopted lymphnode metastasis measuring $3 \mathrm{~cm}$ or larger as a factor of high risk [11]. We analyzed this issue in our series and obtained similar results [50]. In the same series, we also found that extranodal tumor extension to adjacent organs requiring the dissection of these organs that was predominantly evaluated 


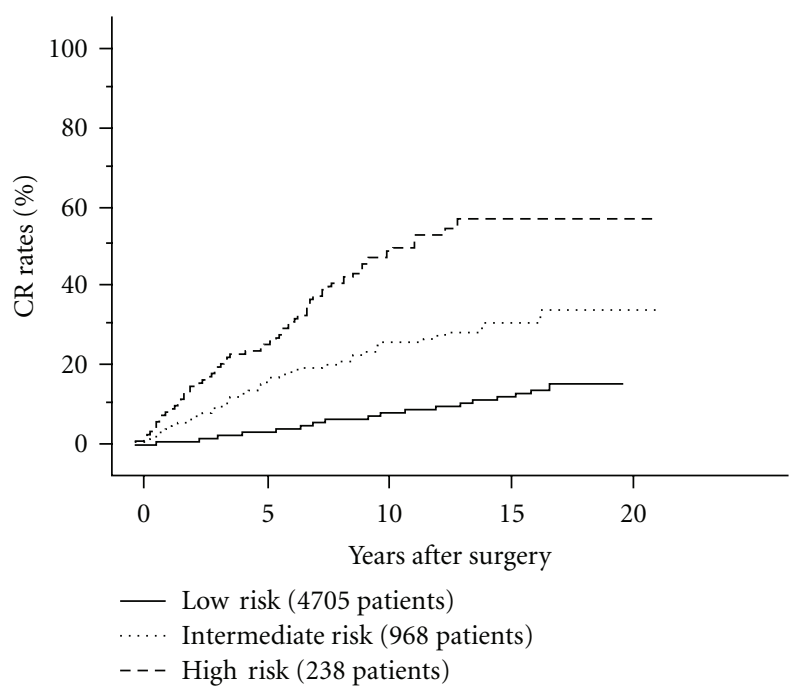

(a)

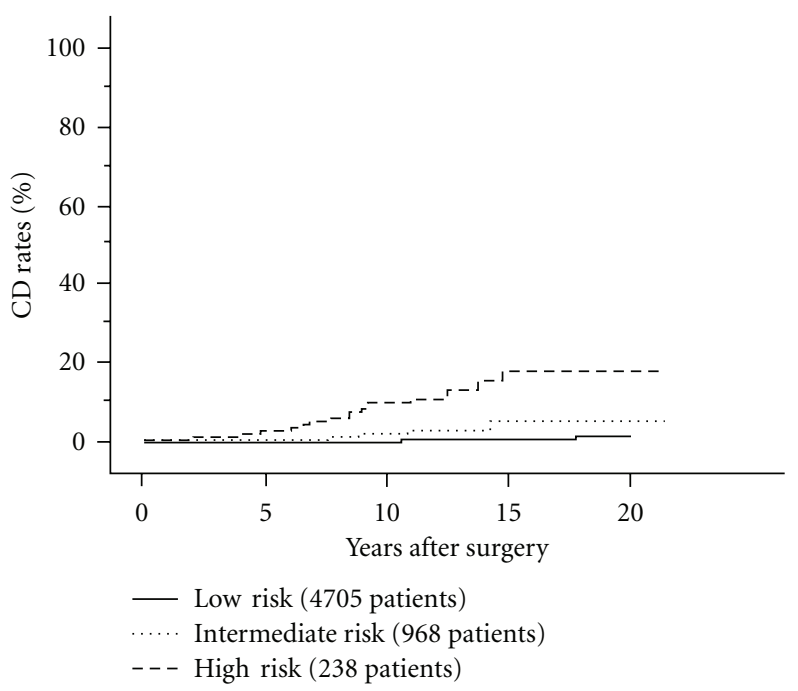

(b)

FIGURE 6: CR rates of PTC patients with low risk, intermediate risk, and high risk for lymph-node metastasis.

on intraoperative findings had a significant prognostic value especially for CSS as indicated below [14, 50, 51].

Taken together, it is currently considered that the prognostic impact of clinical node metastasis can be divided into three categories: (1) clinical node metastasis measuring $3 \mathrm{~cm}$ or larger or showing extranodal tumor extension on intraoperative findings (high risk), (2) clinical node metastasis smaller than $3 \mathrm{~cm}$ without extranodal tumor extension (intermediate risk), and (3) no clinical node metastasis (lowrisk). Figures 6(a) and 6(b) indicate carcinoma recurrence rate and carcinoma death rate of three categories for carcinoma recurrence rate and carcinoma death rate.

2.2.4. Distant Metastasis at Surgery (M1). Although rarer than FTC, PTC can metastasize not only to regional lymph nodes, but also to distant organs such as the lung, bone, and brain. Distant metastasis at surgery can be detected on imaging studies such as CT scan and PET-CT and also on postoperative radioactive iodine (RAI) ablation or whole body scan.

There are no doubts that distant metastasis at surgery is one of the most important prognostic factors for CSS of patients [14]. However, prognosis of M1 patients differs according to other clinicopathological features of the patient. Many previous studies analyzed M1 patients and patients showing distant recurrence during postoperative followup as a single group and/or analyzed PTC and FTC as DTC in a single group [52-55]. In our opinion, these should be separately analyzed as described in the Introduction. In the subset of M1 patients with PTC in our series, M1 is directly linked to other clinicopathological features such as gender, tumor size, extrathyroid extension, and $\mathrm{N}$ factor, indicating that distant metastasis at diagnosis will more likely be found in PTC showing aggressive behavior [56]. Tumor larger than $4 \mathrm{~cm}$, aged 55 years or older (at the time of initial surgery) and extrathyroid extension were independent prognostic factors for CSS of M1 PTC patients (Figures 7(a), 7(b), and $7(\mathrm{c})$ ). Distant metastasis to organs other than the lung also reflected worse CSS of patients on univariate analysis. Furthermore, although there was no significant difference, CSS of M1 patients whose distant metastases were refractory to RAI therapy was also adverse.

Taken together, the prognosis of M1 patients depends on clinicopathological features of the primary lesion.

\subsection{Prognostic Factors Predominantly Based on Intraoperative Findings}

2.3.1. Extrathyroid Extension. Extrathyroid extension has been adopted in various classification systems [10-13]. In the UICC TNM classification system, there are two grades of extrathyroid extension [11]. Extension to perithyroid tissue and sternothyroid muscle was graded as T3 (minimal extension), and extension to other adjacent organs such as the recurrent laryngeal nerve, esophagus, trachea, sternohyoid muscle, and jugular vein was graded as T4 (massive or significant extension). However, this classification has some limitations. Firstly, this classification system is established for preoperative evaluation. However, it is significantly difficult to accurately evaluate extrathyroid extension based on preoperative evaluation unless recurrent laryngeal nerve paralysis due to carcinoma invasion and apparent intratracheal extension on CT scan or MRI can be detected. Most extrathyroid extensions are found on intraoperative findings, indicating that $\mathrm{T}$ classification based on preoperative findings is not appropriate. It is almost impossible to detect T3 based on preoperative findings and evaluation of T4 on preoperative findings is also much more inaccurate than that on intraoperative findings. Secondly, our previous studies showed that T3 did not affect patient prognosis either on intraoperative or pathological evaluation $[57,58]$. In UICC 


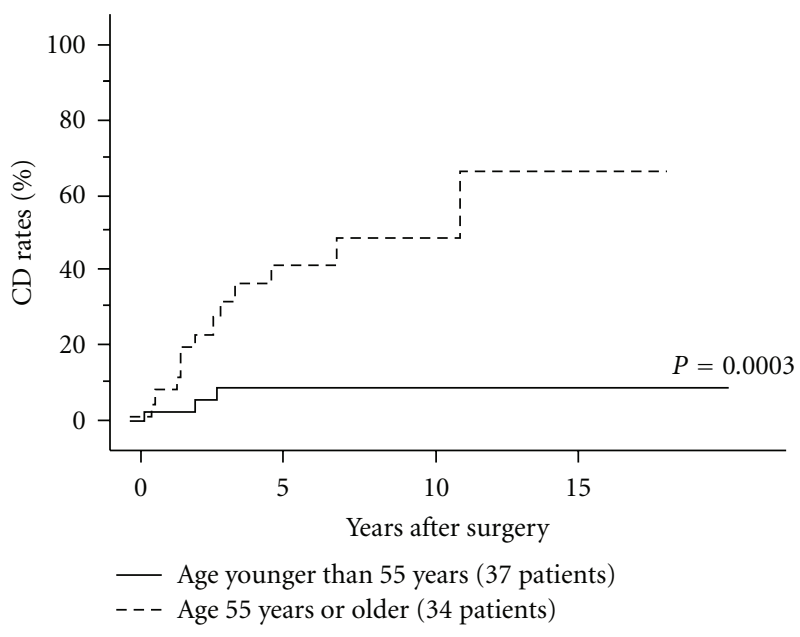

(a)

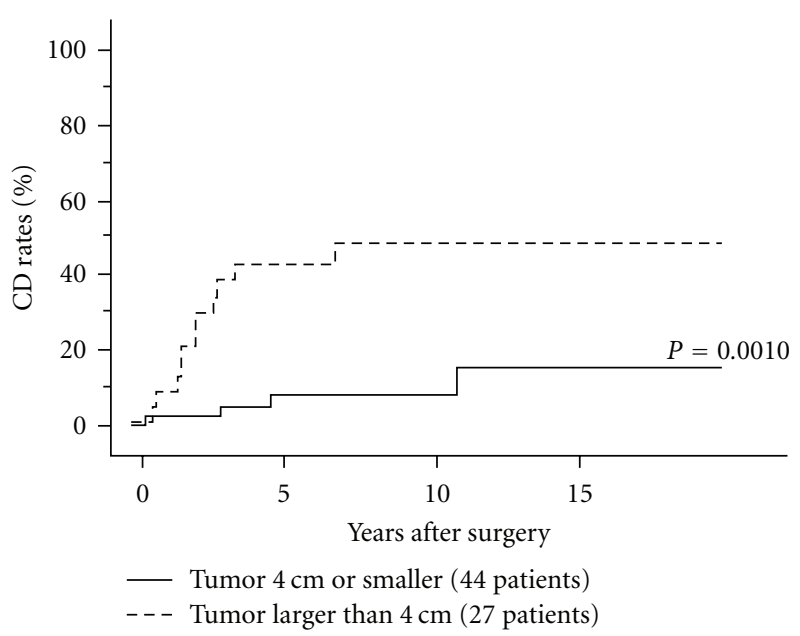

(b)

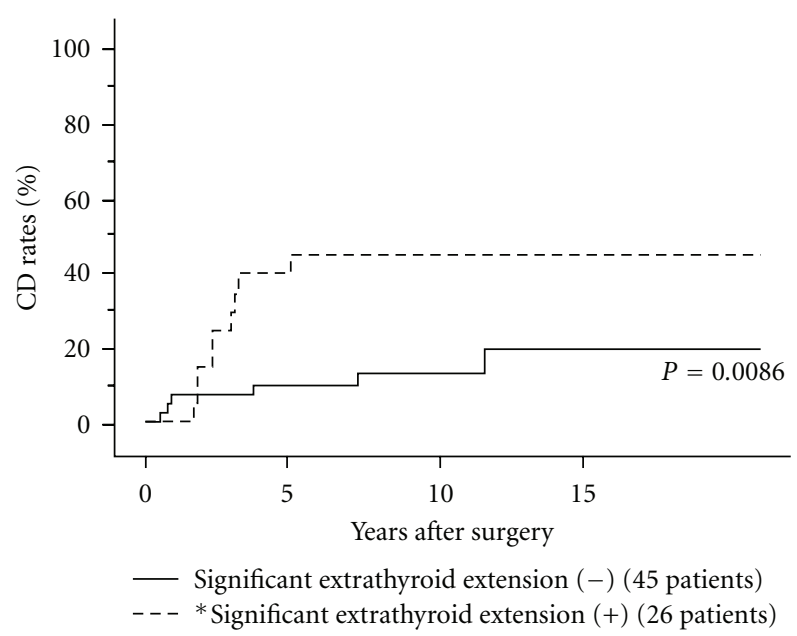

(c)

FIGURE 7: (a) CD rates of M1 patients with PTC aged 55 years or older and those aged younger than 55 years. (b) CD rates of M1 patients with PTC having tumor $4 \mathrm{~cm}$ or smaller and those having tumor larger than $4 \mathrm{~cm}$. (c) CD rates of M1 PTC patients with and without extrathyroid extension. *Except for recurrent laryngeal nerve and cricothyroid or inferior constrictor muscle.

TNM classification, tumors measuring $4 \mathrm{~cm}$ or less are upgraded to T3 if they showed minimal extension, but we proposed that such an upgrade should be abolished based on our data. In our institution, only significant extrathyroid extension on intraoperative findings is adopted as a factor indicating aggressive behavior.

Our recent study showed that the significance of extrathyroid extension is not uniform but rather size-dependent. Prognostic significance of extrathyroid extension was less than clinical lateral node metastasis (N1b) for PTC measuring $3 \mathrm{~cm}$ or less, it was reversed in PTC larger than $3 \mathrm{~cm}$ [59]. In the intraoperative staging system that we established by revising the UICC TNM staging system, extrathyroid extension of tumor larger than $2 \mathrm{~cm}$ was regarded as a sign of high risk and that of a tumor $2 \mathrm{~cm}$ or smaller was a sign of intermediate risk [14].

We currently conclude that extrathyroid extension should be evaluated on intraoperative findings and that minimal extension to perithyroid tissue and the sternothyroid muscle should not be considered significant. Significant extension on intraoperative evaluation is an important factor predicting a worse prognosis for patients with PTC, especially those with a large tumor.

2.3.2. Extranodal Tumor Extension. Prognostic significance of extranodal tumor extension has been investigated by several groups including ours [14, 50, 51, 60-62]. Yamashita et al. showed that patients with pathological extranodal tumor extension were more likely to show distant recurrence [61]. In our series, as indicated above, extranodal tumor extension requiring resection of adjacent organs showed a worse prognosis, especially for CSS as indicated above [14, $50,51]$. It is strongly suggested that PTC with extranodal tumor extension is high risk and has a high potential to show a dire prognosis. 


\subsection{Prognostic Factors Based on Postoperative Findings}

2.4.1. Pathological Lymph-Node Metastasis. PTC frequently metastasizes to the regional lymph nodes [63-65]. As indicated above, clinical lymph-node metastasis detected on preoperative imaging studies is a significant prognostic factor, and especially, large metastatic node has a very strong prognostic impact on both DFS and CSS of PTC patients. However, diagnostic accuracy of ultrasonography for lymph-node metastasis is actually not very high. Our previous study showed that the positive predictive value (PPV) and specificity of ultrasonography for central node metastasis were $92 \%$ and $98 \%$, respectively, but the negative predictive value (NPV) and sensitivity were only $37 \%$ and $12 \%$, respectively, [15]. For lateral node metastasis, PPV and specificity were 95\% and 97\%, respectively, and NPV and sensitivity were $43 \%$ and $29 \%$, respectively, [15]. Diagnostic accuracy of ultrasonography for lateral node metastasis is a little better than that for central node metastasis, but these findings indicate that small and latent metastasis to the regional lymph nodes is frequently overlooked on ultrasonography. However, according to our data, such latent metastases do not markedly affect patient prognosis. Pathological and latent node metastases increase the rate of carcinoma recurrence to some extent but do not affect CSS of patients $[32,45]$. In conclusion, lymph-node metastasis that can be diagnosed only on pathological examination is a moderate factor only for PTC recurrence.

2.4.2. Histological Variants. Many histological variants of PTC have been adopted in the WHO classification [4]. Table 1 summarizes the prevalence of histological variants in our series of 1521 PTC patients [66]. Follicular variant was the most common variant, which accounted for $7 \%$. Follicular variant was reported to show aggressive behavior [67-69], but in our series of Japanese patients, prognosis did not differ from that of conventional PTC [66]. Tall cell variant is a typical variant showing an aggressive behavior [70-72] (Figures 8(a) and 8(b)). This accounted for $4 \%$ of our series of PTC patients [73]. Interestingly, the incidence of clinicopathological features reflecting poor prognosis such as gender, clinical lymph-node metastasis, and extrathyroid extension did not differ between tall cell variant and others although the average age of patients with tall cell variant was slightly higher than that of other patients. However, this histology independently affected DFS and CSS of PTC patients on multivariate analysis [73]. Oncocytic variant accounted for $2 \%$ of PTC and most of them were diagnosed as having Warthin-like tumor showing abundant chronic inflammatory cells that are associated with chronic thyroiditis. Previous studies showed that this variant generally had a mild character [74-76], which was identical to our findings, because none of the patients with this oncocytic variant died of carcinoma in our study [66].

There are some more important variants of which prevalence is lower than those indicated above. Columnar cell variant is now classified as an independent entity as columnar cell carcinoma [4]. This carcinoma accounted only for $0.4 \%$, but as much as $60 \%$ of patients showed
TABLE 1: Prevalence of conventional and various histologic variants in 1521 papillary carcinomas.

\begin{tabular}{lc}
\hline Conventional & $86 \%$ \\
Follicular variant & $7 \%$ \\
Tall cell variant & $4 \%$ \\
Oncocytic variant & $2 \%$ \\
Columnar cell variant & $0.4 \%$ \\
Macrofollicular variant & $0.3 \%$ \\
Diffuse sclerosing variant & $0.3 \%$ \\
Cribriform morular variant & $0.1 \%$ \\
Others & $0.1 \%$ \\
\hline
\end{tabular}

carcinoma recurrence, indicating that this histologic type is a sign of significantly aggressive behavior [66]. Regarding the biological behavior and prognosis of the diffuse sclerosing variant, previous studies showed discrepant findings [7779]. In our study, the diffuse sclerosing variant frequently showed multiple clinical node metastases and was more likely to show PTC recurrence, but the CSS of patients did not differ from that of conventional PTC [80]. Macrofollicular variant could be diagnosed as multinodular goiter in the past in high incidences $[81,82]$. In our study, it shows an indolent character, similar to reports from Western countries [83]. Cribriform morular variant is mostly a hereditary disease caused by the APC gene mutations associated with colonic polyposis or colon carcinoma [84]. This variant is multicentric and total thyroidectomy is mandatory regardless of carcinoma size and lymph-node status, but the prognosis of patients is generally excellent [85].

Although not adopted in the WHO classification, encapsulated, PTC generally shows a better prognosis than conventional PTC. This type is encapsulated and there is no extrathyroid extension, which may be the reason for excellent prognosis. The incidence of lymph-node metastasis is also lower than that in conventional PTC $[86,87]$.

2.4.3. Involvement of PDC Components. As indicated in Section 1, three criteria for PDC have been proposed. There are three growth patterns of PDC, solid, trabecular, and insular growth patterns, which are designated as PDC components. In order to diagnose PDC using the WHO classification, PDC components should occupy in the majority of the tumor [4]. However, in the JSTS criteria [5], carcinoma with only a small portion of PDC components is diagnosed as PDC and discriminated from PTC or FTC. In the criteria for PDC in the Turin proposal [6], the absence of nuclear features of PTC and the presence of convoluted nuclei, mitotic activity $(3 \times 10 \mathrm{HPF})$, or tumor necrosis were adopted in addition to the presence of a PDC component.

At present, PDC is considered as an independent entity from PTC and FTC in WHO classification [4] and JSTS [5], and it may be better to describe PDC in an independent chapter. However, the diagnostic criteria for PDC have not yet been consolidated. Thus, in this paper, the involvement of PDC components is regarded as one of the pathological features of both PTC and FTC. 


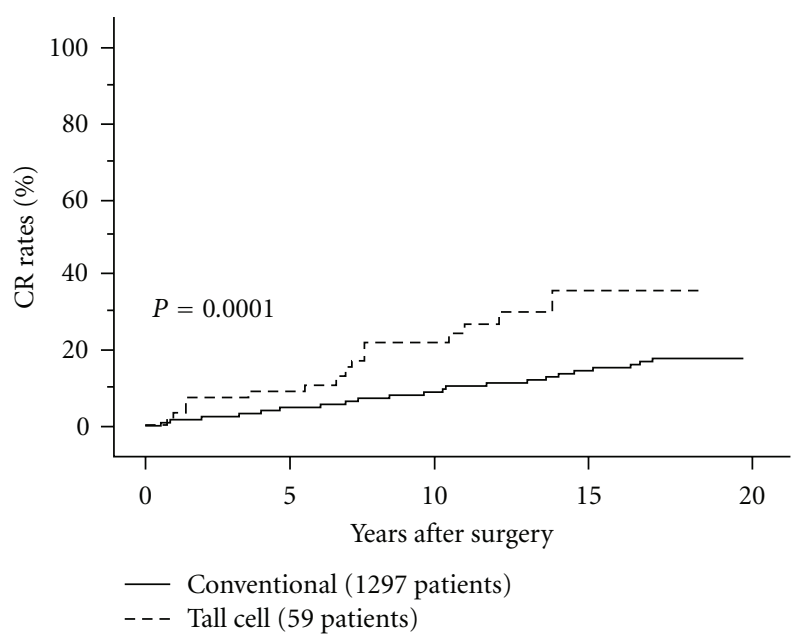

(a)

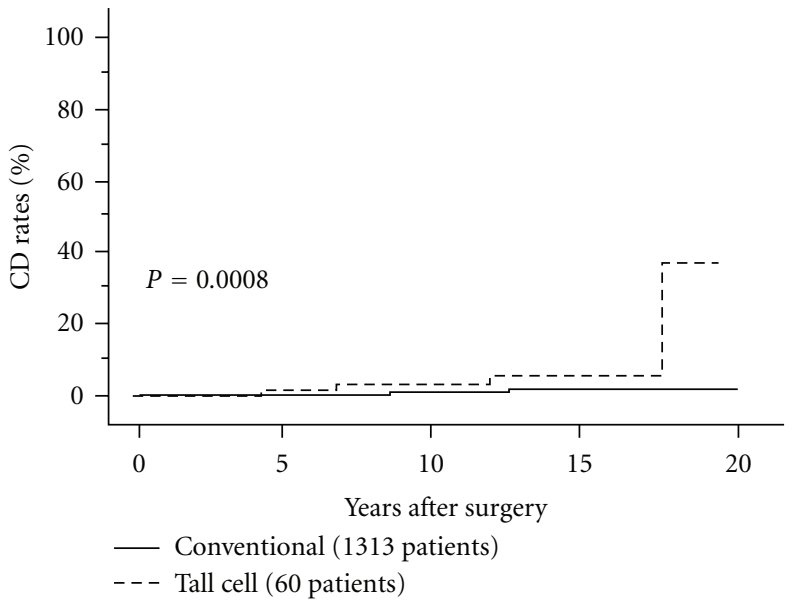

(b)

FIGURE 8: CR rates of tall cell variant and conventional PTC.

Actually, few studies have been published regarding the prevalence of PDC based on all three criteria in one series of patients. In our series, the prevalences of PDC based on JSTS guidelines, the WHO classification, and the Turin proposal were $11 \%, 0.8 \%$, and $0.3 \%$, respectively, in our PTC series [73]. This suggests that, in most cases, PDC components are present only in a small portion of carcinoma lesions. In our series, the 10-year DFS rates of PTC with and without PDC components were $88.8 \%$ and $77.0 \%$, respectively, and the CSS rates were $94.2 \%$ and $98.4 \%$, respectively. On multivariate analysis, the presence of PDC components independently reflected DFS but not CSS of patients. Based on these findings, it does not seem appropriate for PTC with limited PDC components (PDC on JSTS) to be classified as an independent entity. A recent study from Japan, however, demonstrated that DTC having a PDC component comprising $10 \%$ or more of the carcinoma lesion had a dire prognosis [88] and publications from other institutions are expected to elucidate this issue. In our series, the 10-year DFS and CSS rates of patients with PDC according to the WHO classification were $54 \%$ and $80 \%$, respectively, and it is considered reasonable to regard this carcinoma as an independent entity. Patient with PDC according to the Turin proposal accounted for only $0.3 \%$ in this series, and the 10 -year DFS and CSS were $25 \%$ and $60 \%$, respectively. This carcinoma has a significantly more aggressive character, but in Japan, the incidence is very small compared with that in Europe and the United States $[89,90]$.

2.4.4. Cell Proliferating Activity. Cell proliferating activity is regarded as an important biological behavior of human carcinoma. There are some markers for evaluation of cell proliferating activity, mitotic figure count (MFC), proliferating cell nuclear antigen (PCNA), and Ki-67. In PTC, however, cell proliferating activity is generally low. MFC that is evaluated on hematoxylin and eosin-stained tissue sections reflects only the index of mitotic cells, indicating that it is difficult to evaluate in PTC [91]. PCNA and Ki67 can be evaluated by immunohistochemistry. The former is a cell cycle-related protein showing an elevated expression level in cells exclusively in the G1-S phase [92]. Ki-67 is a protein expressed in the cell nuclei in all cells except those in the G0 phase [93]. Therefore, labeling index (LI) of PCNA should be smaller than Ki-67 LI, but previous studies showed that PCNA LI was generally higher than Ki-67 LI $[94,95]$. Furthermore, PCNA LI were reported not to correlate with Ki-67 LI or MFC [94], indicating that PCNA is an unreliable marker for evaluation of cell proliferating activity.

Therefore, it is concluded that Ki-67 LI is the most useful marker for evaluation of cell proliferating activity for PTC. Interpretation of Ki-67 LI data varies according to the origin of carcinoma, but counting Ki-67 LI in hot spots is generally accepted for PTC, because Ki-67 LI in PTC is mostly low. Previous reports examined Ki-67 LI in specimens obtained from FNAB and found that Ki-67 LI $\geq 4 \%$ predicted a worse CSS [96]. However, FNAB specimens are not always collected from hot spots, indicating that FNAB specimens with low Ki-67 LI do not always reflect low proliferating activity of PTC tissue. In our previous study, Ki-67 LI directly related to extrathyroid extension, patient age, and distant metastasis at surgery [97]. Furthermore, Ki-67 LI > 1\% and $>3 \%$ were independent prognostic factors for DFS and CSS, respectively, (Figures 9(a) and 9(b)). The optimal cutoff of LI should be determined in each institution, but PTC with high Ki-67 LI should be carefully followed.

2.4.5. BRAF Gene Mutation. BRAF is a Raf kinase and a potent activator of the MAPK pathway contributing largely to cell proliferation, apoptosis, survival, and tumorigenesis [98-100]. BRAF mutation has been detected in various human malignancies and the hot-spot mutation is a thymine-to-adenine transversion at nucleotide 1799 (T1799A) on exon 15, resulting in a valine-to-glutamate substitution at residue 600 (V600E) [101]. In thyroid carcinoma, studies for BRAF mutation have been actively performed. 


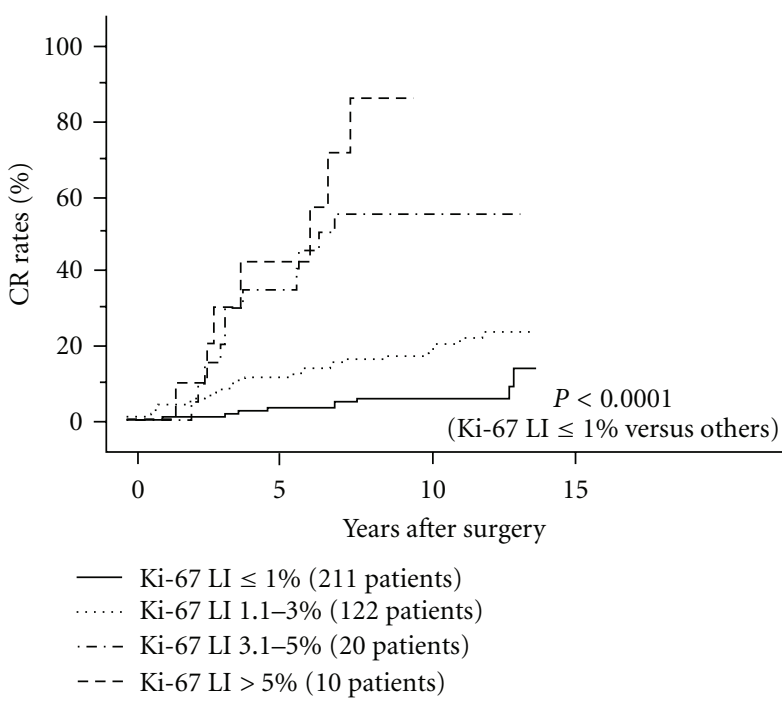

(a)

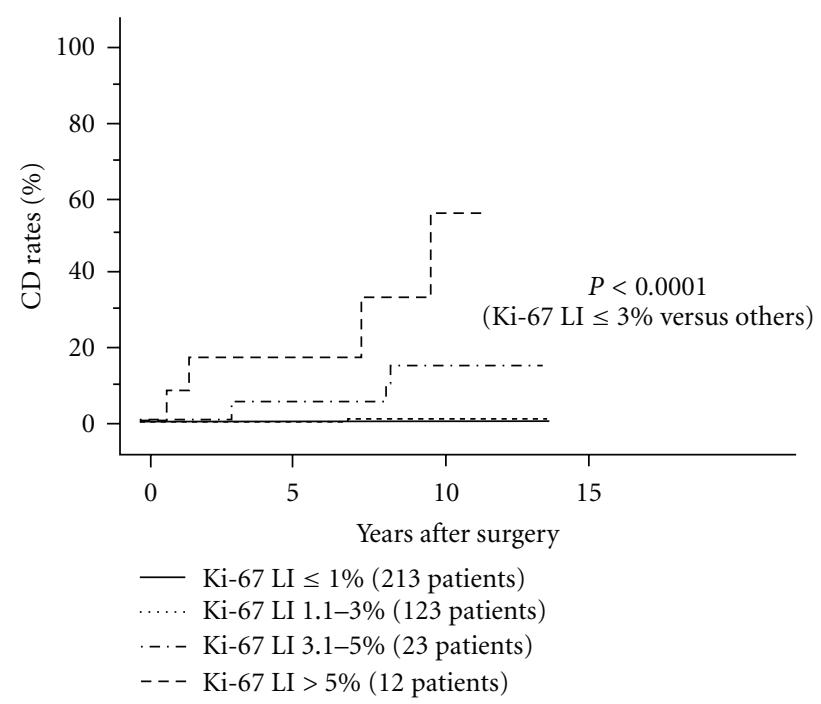

(b)

FIGURE 9: CR rates of PTC patients with Ki-67 1\% or less, 1.1-3\%, 3.1-5\%, and greater than 5\%.

This event was exclusively detected in PTC and its prevalence ranged from $28 \%$ to $83 \%$ [102-109]. Reports from Western countries and some Asian countries demonstrated that the prognosis of PTC with BRAF mutation was significantly worse than that with no mutation [102, 103, 105-109].

In our data analyzing 631 patients, however, BRAF mutation was not linked to any clinicopathological features of PTC patients or affected prognosis of patients even on univariate analysis [110]. Its prevalence varies according to histology, and it was higher in tall cell variant and lower in follicular variant than in conventional PTC, which was not discrepant with previous studies $[111,112]$.

Although there seems to be a consensus that BRAF mutation significantly reflects an aggressive character in PTC in Western countries and some Asian countries, its role remains unclear in Japan, because there have not been any other studies in a large number of patients with long-term followup, to date.

2.5. Discussion and Summary. Due to the prevalence of ultrasonography-guided FNAB, most PTC can be diagnosed before surgery. There are several important prognostic factors for PTC based on patient backgrounds and findings on preoperative imaging studies. Furthermore, some prognostic factors are evaluated based on intraoperative findings. Therefore, the biological behavior, including prognosis of patients, of PTC can generally be evaluated before the end of surgery. Pathological evaluation is less significant than preoperative and intraoperative evaluations, but it is still important to diagnose certain variants and the involvement of PDC components, both of which affect patient prognoses.

Based on the series in our study, the important prognostic factors of PTC patients are age 55 years or older, distant metastasis at surgery, clinical lymph-node metastasis measuring $3 \mathrm{~cm}$ or larger, extranodal tumor extension, and significant extrathyroid extension (especially for large PTC, e.g., larger than $2 \mathrm{~cm}$ ). Tumor larger than $4 \mathrm{~cm}$, clinical node metastasis smaller than $3 \mathrm{~cm}$ with no extranodal tumor extension, and male gender are moderate prognostic factors. Latent node metastasis detected only on pathological examination and multicentricity can be prognostic factors but the impact of these is low.

Apart from the above, there are some important pathological findings affecting prognosis. Tall cell variant, columnar cell variant, and involvement of PDC components in the majority of the carcinoma lesion are significant prognostic factors on pathological examination. High Ki-67 LI might be a predictor of a dire prognosis. Presence of limited PDC components is also a moderate to weak prognostic factor, because it predicts a worse DFS but not CSS. Table 2 summarizes the risk factors of PTC based on preoperative, intraoperative and pathological evaluations.

\section{Prognostic Factors of FTC}

FTC is only occasionally diagnosed on preoperative cytology, which is in sharp contrast to PTC. Most patients with FTC undergo hemithyroidectomy based on the preoperative diagnosis as follicular tumor or adenomatous nodules. Generally, patients are diagnosed as having FTC on postoperative pathological examination. FTC is less likely to metastasize to the regional lymph node and lymph-node dissection is rarely performed in surgery for patients suspected of FTC. Extrathyroid extension is also a rare event and in our series, only $2 \%$ of patients showed an extension to adjacent organs [113]. Therefore, prognostic factors of FTC based on preoperative findings were less significant than those of PTC.

\subsection{Prognostic Factors Based on Patient Backgrounds}

3.1.1. Patient Age. Patient age has been adopted as a significant prognostic factor for FTC [114-119]. In our series of 
TABLE 2: Risk classification of TPC based on preoperative, intraoperative, and pathological findings.
High risk
(a) Patients having distant metastasis at presentation.
(b) Patients including PDC components in majority of carcinoma lesions.
(c) Patients diagnosed as tall cell variant.
(d) Patients 55 yrs or older and having one of the following three:
(1) tumor size $>2 \mathrm{~cm}$ with extension to adjacent organs, (corresponding to T4),
(2) lymph-node metastasis $>3 \mathrm{~cm}$,
(3) lymph-node metastasis extending to adjacent organs
Intermediate risk
(a) Patients including PDC component in small portion of carcinoma lesions.
(b) Patients 55 yrs or older and having one of the following three:
(1) tumor size $>4 \mathrm{~cm}$ (excluding T4 cases),
(2) tumor size $\leq 2 \mathrm{~cm}$ with extension to adjacent organs (corresponding to T4),
(3) lymph-node metastasis detectable on preoperative imaging studies $\leq 3 \mathrm{~cm}$ and without extension to adjacent organs

Low risk

(a) Patients under 55 yrs without distant metastasis at diagnosis.

(b) Patients 55 yrs or older who are not classified as high risk or intermediate risk

334 patients, age 45 years or older had a prognostic impact for CSS on univariate analysis but was not an independent prognostic factor [113]. Interestingly, in contrast to PTC, age cutoff at 45 years had the strongest prognostic impact in our series.

3.1.2. Gender. Some previous studies demonstrated the prognostic impact of gender of FTC patients $[16,119,120]$. In our series, male patients tended to show recurrence only on univariate analysis (Figure 10). However, male gender did not show any prognostic impact on CSS of patients.

\subsection{Prognostic Factors Based on Preoperative Evaluation}

3.2.1. Clinical Lymph-Node Metastasis. Since it is rare for FTC to show clinically apparent node metastasis, it is difficult to evaluate its prognostic value. However, as indicated below, we demonstrated that 10 of 11 patients showing pathological node metastasis showed an aggressive pathology such as PDC or widely invasive carcinoma [113], indicating that FTC with clinically apparent node metastasis is progressive and shows an aggressive behavior.

3.2.2. Distant Metastasis at Surgery. Undoubtedly, this is an important prognostic factor as shown in previous studies including ours [16, 113-122]. Five-year CSS of patients with distant metastasis at surgery was around 55\% in our series [113]. Distant metastasis at surgery was directly linked to age 45 years or older, lymph-node metastasis, invasive grade, and poor differentiation in our series. For CSS, distant metastasis at surgery or locally palliative surgery was the most important prognostic factor on multivariate analysis.

3.2.3. Tumor Size. Relationship between tumor size and prognosis has been reported $[120,121]$. We previously demonstrated that tumor larger than $4 \mathrm{~cm}$ affected both DFS

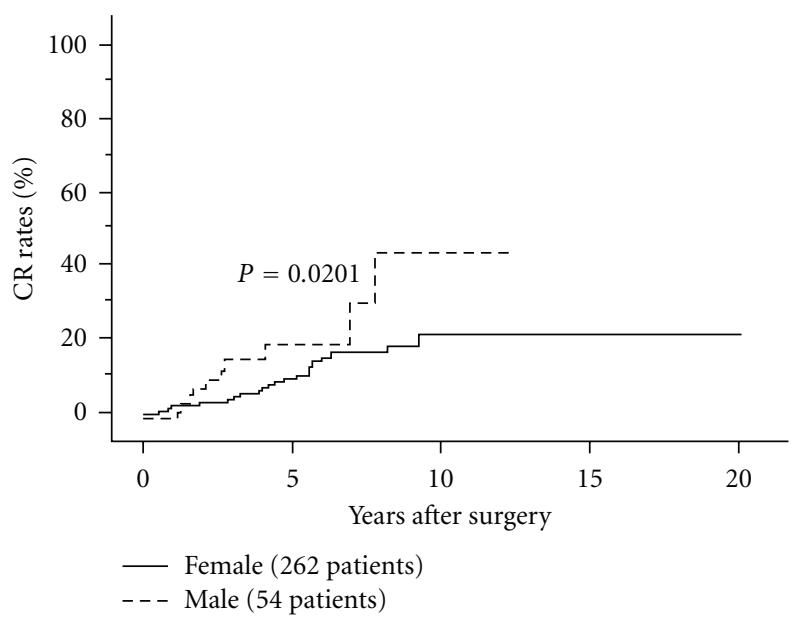

FIGURE 10: CR rates of female and male FTC patients.

and CSS patients on univariate analysis. On multivariate analysis, tumor size had a marginal significance for DFS, but not for CSS.

3.2.4. Family History. Familial FTC accounted for $1.4 \%$ of FTC in Japan, but prognosis of these cases did not differ from that of FTC with no family history [123]. To date, there have not been any other reports regarding this issue.

\subsection{Prognostic Factors Based on Intraoperative Findings}

3.3.1. Extrathyroid Extension. As indicated above, extrathyroid extension is a rare event for FTC in Japan. In our series, all patients who showed extrathyroid extension were diagnosed as having PDC components [113]. It is, therefore,suggested that extrathyroid extension is an unusual event for FTC but predicts an adverse prognosis. 


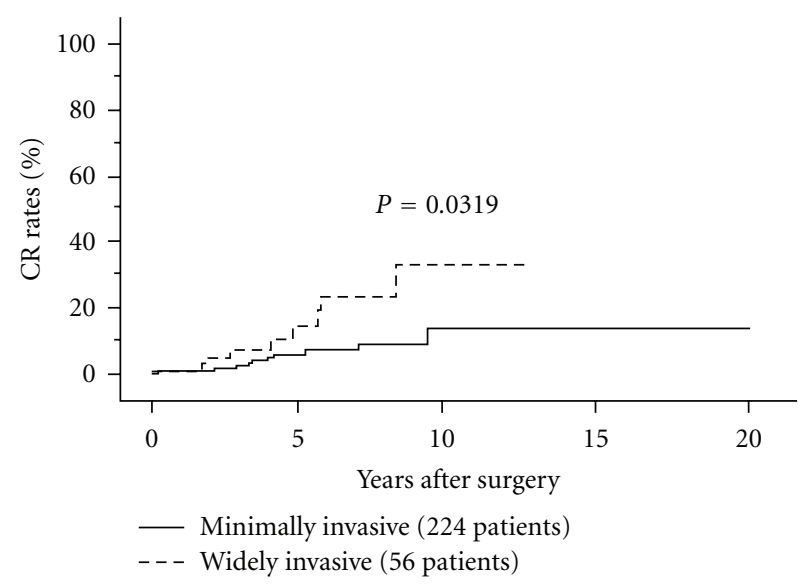

(a)

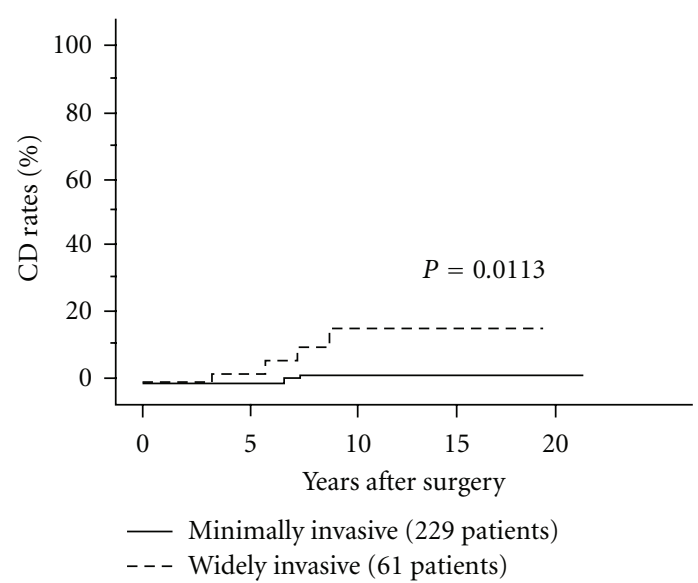

(b)

FIGURE 11: CR rates of minimally and widely invasive FTC.

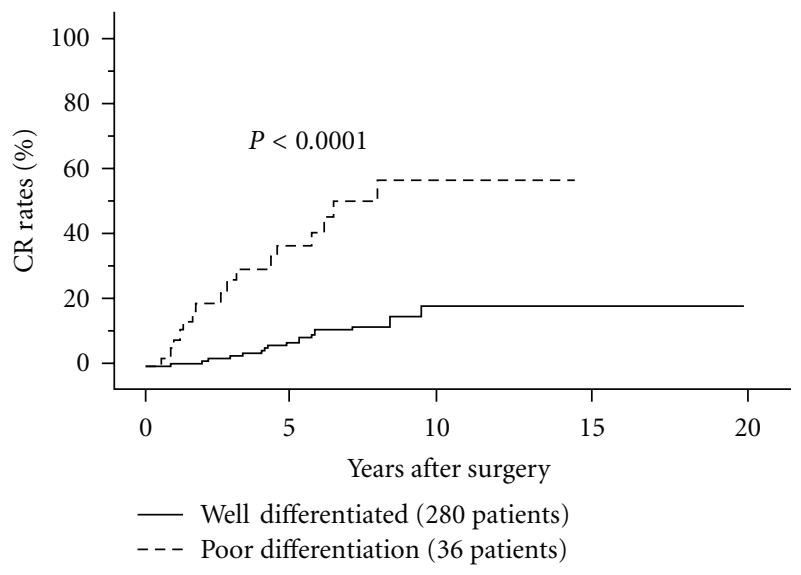

(a)

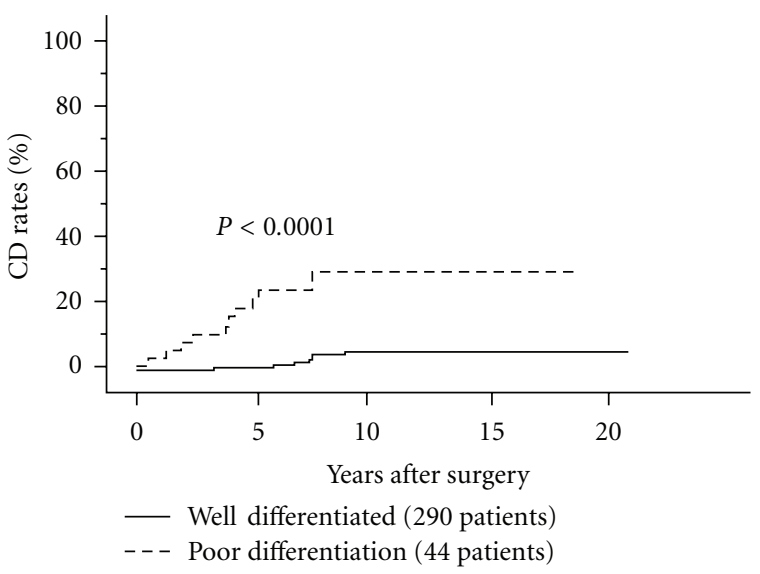

(b)

Figure 12: CR rates of FTC patients with and without PDC components.

\subsection{Prognostic Factors Based on Pathological Examination}

3.4.1. Degree of Invasiveness. FTC is pathologically diagnosed when it shows capsular and/or vascular invasion of tumor cells. FTC is divided into two categories: (1) minimally invasive FTC, small number of invasive sites can be only histologically detected and (2) widely invasive FTC, invasive sites, and/or vascular invasion are extensively present and even grossly detected. Previous studies demonstrated that widely invasive FTC was more likely to show recurrence and had a poorer prognosis than minimally invasive FTC [113, $124,125]$. Especially, extensive vascular invasion significantly affects prognosis of FTC. Therefore, it is very important to diagnose whether an FTC is widely or minimally invasive on pathological examination to predict patient prognosis and select the subsequent therapy. In our series, carcinoma recurrence rates and carcinoma death rates of patients with widely invasive FTC were significantly greater than those of patients with minimally invasive FTC [113] (Figures 11(a) and $11(\mathrm{~b}))$. Since most FTC patients underwent hemithyroidectomy in initial surgery, we recommend completion total thyroidectomy followed by RAI ablation for widely invasive FTC patients but not for minimally invasive FTC patients unless no distant metastases were detected.

3.4.2. Poor Differentiation. Involvement of PDC component is a more significant prognostic factor for FTC than that for PTC. In our experience, PDC arising from FTC is generally diagnosed as PDC on WHO classification, because of the presence of PDC component in the majority of the tumor. In our series, 5-year and 10-year carcinoma recurrence rates of FTC having PDC component were $37 \%$ and $57 \%$, and its carcinoma death rates were $21 \%$ and $29 \%$, respectively [113] (Figures 12(a) and 12(b)). On multivariate analysis, this is the strongest prognostic factor for DFS. For CSS, this had the second strongest prognostic impact after distant metastasis at surgery.

3.4.3. Oxyphilic Cell Variant. Oxyphilic cell variant is a particular type of FTC on WHO classification. Wide cytoplasms with eosinophilic granules and clear nuclear bodies 
TABLE 3: Risk classification of FTC based on preoperative, intraoperative, and pathological findings.

\begin{tabular}{l}
\hline High risk \\
Patients having one of the following three: \\
(1) patients having PDC components in the majority of carcinoma lesions, \\
(2) patients diagnosed with widely invasive carcinoma (extensive capsular or vascular invasion), \\
(3) patients having distant metastasis at diagnosis. \\
Intermediate risk \\
Patients without high-risk characteristics and having one of the following two: \\
$\quad$ (1) patients 45 yrs or older, \\
$\quad$ (2) patients having tumor $>4$ cm. \\
Low risk \\
Patients who are not classified as high-risk or intermediate risk \\
Patients with extrathyroid extension and lymph-node metastasis may be classified into high and intermediate risk, respectively.
\end{tabular}

are typical findings on hematoxylin and eosin-stained tissue sections. One study showed that most cases of oxyphilic cell variant were RAI refractory [126]. In Europe and the United States, many researchers have demonstrated a worse prognosis of oxyphilic cell variant than conventional FTC $[116,126,127]$. However, there are studies demonstrating that prognosis of oxyphilic cell variant does not differ from $[128,129]$ or was even better than that of conventional FTC [130]. In Japan, there are two studies investigating the prognosis of oxyphilic cell variant and both demonstrated that the prognosis of oxyphilic cell variant was similar to that of conventional FTC $[113,131]$. It is, therefore, not evident that oxyphilic cell variant shows an aggressive behavior in Japan. The prevalence of oxyphilic cell variant was 13\% in our series [113], which is similar to that in the United States [116].

3.4.4. Pathological Lymph-Node Metastasis. Lymph-node dissection is not performed for surgery for patients unless metastatic nodes are clinically detected or cytological examination suggests high-grade malignancy such as PDC. In our series, 11 of 334 patients (3\%) had pathologically diagnosed lymph-node metastasis and 10 of these patients were diagnosed as having widely invasive FTC or PDC as indicated above [113]. During postoperative followup, 10 patients $(3 \%)$ showed recurrence to the regional lymph nodes after surgery and 8 of these were widely invasive carcinoma or included PDC components in specimens in initial surgery. Therefore, although rare, the presence of lymph-node metastasis reflects aggressive behavior of FTC. A report form Germany also demonstrated the prognostic impact of lymph-node metastasis of FTC and recommended extensive lymph-node dissection, including MND, for FTC demonstrating a large tumor and/or extrathyroid extension [120].

3.5. Discussion and Summary. In contrast to PTC, FTC can rarely be diagnosed on preoperative examinations, including ultrasonography and cytology. The most significant prognostic factor was the presence of distant metastasis at surgery. Apart from that, pathological findings such as the involvement of PDC components and widely invasive lesions were significant prognostic factors. Although oxyphilic cell variant did not affect prognosis in studies from Japan, many studies from Western countries indicated that this variant is a sign of aggressive behavior. Taken together, pathological evaluation of FTC is very important to predict patient prognosis and select the therapeutic strategy such as whether completion total thyroidectomy should be performed. Patient age, gender, and tumor size have a moderate prognostic impact. Table 3 summarizes the risk classification of FTC. In addition, extrathyroid extension and pathological lymph node metastasis are rare events in FTC, but these findings are much more likely detected in patients showing an aggressive histology. Although these findings can be signs of aggressive behavior, it remains unclear whether they are independent prognostic factors.

\section{Conclusions}

The significance of preoperative evaluation and pathological examination differs between PTC and FTC. For PTC, preoperative findings on imaging studies and intraoperative findings are quite important to evaluate biological behavior, including prognosis, and therapeutic strategies can be established for most patients at that time. Distant metastasis at surgery, extrathyroid extension, large lymphnode metastasis, and extranodal tumor extension are significant prognostic factors and extensive surgery and adjuvant therapy with careful followup are mandatory for patients with such characteristics.

In contrast, postoperative pathological examination has a significant value not only for diagnosis of FTC but also for evaluating biological characteristics. Similar to PTC, distant metastasis at surgery is the strongest prognostic factor, but pathological findings such as grade of invasiveness and carcinoma differentiation are also very important to evaluate its biological behavior. Such pathological findings are essential to decide whether to perform further therapies such as completion total thyroidectomy with RAI therapy for FTC. 


\section{References}

[1] T. Ito, T. Seyama, T. Mizuno et al., "Unique association of p53 mutations with undifferentiated but not with differentiated carcinomas of the thyroid gland," Cancer Research, vol. 52, no. 5, pp. 1369-1371, 1992.

[2] A. Sakamoto, N. Kasai, and H. Sugano, "Poorly differentiated carcinoma of the thyroid. A clinicopathologic entity for a high-risk group of papillary and follicular carcinomas," Cancer, vol. 52, no. 10, pp. 1849-1855, 1983.

[3] M. L. Carcangiu, G. Zampi, and J. Rosai, "Poorly differentiated ('insular') thyroid carcinoma. A reinterpretation of Langhans' 'wuchernde struma,' American Journal of Surgical Pathology, vol. 8, no. 9, pp. 655-668, 1984.

[4] M. Sobrinho-Simoes, M. L. Carcangiu, J. Albores-Saavedra et al., "Poorly differentiated carcinoma," in Pathology and Genetics of Tumous of Endocrine Organs, R. A. DeLeillis, R. V. Lloyd, P. U. Heitz et al., Eds., pp. 73-76, IARC Press, Lyon, France, 2004.

[5] The Japanese Society of Thyroid Surgery, General Rules for the Description of Thyroid Cancer, Kanehara Press, Tokyo, Japan, 6th edition, 2005.

[6] M. Volante, P. Collini, Y. E. Nikiforov et al., "Poorly differentiated thyroid carcinoma: the Turin proposal for the use of uniform diagnostic criteria and an algorithmic diagnostic approach," American Journal of Surgical Pathology, vol. 31, no. 8, pp. 1256-1264, 2007.

[7] Y. Ito, N. Amino, T. Yokozawa et al., "Ultrasonographic evaluation of thyroid nodules in 900 patients: comparison among ultrasonographic, cytological, and histological findings," Thyroid, vol. 17, no. 12, pp. 1269-1276, 2007.

[8] A. Antonelli, P. Miccoli, M. Ferdeghini et al., "Role of neck ultrasonography in the follow-up of patients operated on for thyroid cancer," Thyroid, vol. 5, no. 1, pp. 25-28, 1995.

[9] T. Uruno, A. Miyauchi, K. Shimizu et al., "Usefulness of thyroglobulin measurement in fine-needle aspiration biopsy specimens for diagnosing cervical lymph node metastasis in patients with papillary thyroid cancer," World Journal of Surgery, vol. 29, no. 4, pp. 483-485, 2005.

[10] B. Cady, R. Rossi, I. Hay, K. H. Cohn, and N. W. Thompson, "An expanded view of risk-group definition in differentiated thyroid carcinoma," Surgery, vol. 104, no. 6, pp. 947-953, 1988.

[11] L. H. Sobin and C. H. Wittekindeds, UICC; TNM Classification of Malignant Tumors, Wiley-Liss, New York, NY, USA, 6th edition, 2002.

[12] I. Sugitani, N. Kasai, Y. Fujimoto, and A. Yanagisawa, "A novel classification system for patients with PTC: addition of the new variables of large ( $3 \mathrm{~cm}$ or greater) nodal metastases and reclassification during the follow-up period," Surgery, vol. 135, no. 2, pp. 139-148, 2004.

[13] I. D. Hay, E. J. Bergstralh, J. R. Goellner et al., "Predicting outcome in papillary thyroid carcinoma: development of a reliable prognostic scoring system in a cohort of 1779 patients surgically treated at one institution during 1940 through 1989," Surgery, vol. 114, no. 6, pp. 1050-1058, 1993.

[14] Y. Ito, K. Ichihara, H. Masuoka et al., "Establishment of an intraoperative staging system (iStage) by improving UICC TNM classification system for papillary thyroid carcinoma," World Journal of Surgery, vol. 34, no. 11, pp. 2570-2580, 2010.

[15] Y. Ito and A. Miyauchi, "Prognostic factors and therapeutic strategies for differentiated carcinomas of the thyroid," Endocrine Journal, vol. 56, no. 2, pp. 177-192, 2008.
[16] C. Passler, C. Scheuba, G. Prager et al., "Prognostic factors of papillary and follicular thyroid cancer: differences in an iodine-replete endemic goiter region," Endocrine-Related Cancer, vol. 11, no. 1, pp. 131-139, 2004.

[17] F. D. Gilliland, W. C. Hunt, D. M. Morris, and C. R. Key, "Prognostic factors for thyroid carcinoma: a populationbased study of 15,698 cases from the Surveillance, Epidemiology and End Results (SEER) program 1973-1991," Cancer, vol. 79, no. 3, pp. 564-573, 1997.

[18] T. Y. Kim, S. J. Hong, J. M. Kim et al., "Prognostic parameters for recurrence of papillary thyroid microcarcinoma," $B M C$ Cancer, vol. 14, no. 8, p. 296, 2008.

[19] J. A. Fagin, "Familial nonmedullary thyroid carcinoma-the case for genetic susceptibility," Journal of Clinical Endocrinology and Metabolism, vol. 82, no. 2, pp. 342-344, 1997.

[20] C. Sturgeon and O. H. Clark, "Familial nonmedullary thyroid cancer," Thyroid, vol. 15, no. 6, pp. 588-593, 2005.

[21] D. W. Robinson and T. G. Orr, "Carcinoma of the thyroid and other diseases of the thyroid in identical twins," Archive of Surgery, vol. 70, no. 6, pp. 923-928, 1955.

[22] J. Nemec, J. Soumar, and V. Zamrazil, "Familial occurrence of differential (non medullary) thyroid cancer," Oncology, vol. 32, no. 3-4, pp. 151-157, 1975.

[23] T. Pal, F. D. Vogl, P. O. Chappuis et al., "Increased risk for nonmedullary thyroid cancer in the first degree relatives of prevalent cases of nonmedullary thyroid cancer: a hospital-based study," Journal of Clinical Endocrinology and Metabolism, vol. 86, no. 11, pp. 5307-5312, 2001.

[24] D. E. Goldgar, D. F. Easton, L. A. Cannon-Albright, and M. H. Skolnick, "Systematic population-based assessment of cancer risk in first-degree relatives of cancer probands," Journal of the National Cancer Institute, vol. 86, no. 21, pp. 1600-1608, 1994.

[25] R. F. Grossman, S. H. Tu, Q. Y. Duh et al., "Familial nonmedullary thyroid cancer: an emerging entity that warrants aggressive treatment," Archives of Surgery, vol. 130, no. 8, pp. 892-899, 1995.

[26] F. Triponez, M. Wong, C. Sturgeon et al., "Does familial nonmedullary thyroid cancer adversely affect survival?" World Journal of Surgery, vol. 30, no. 5, pp. 787-793, 2006.

[27] K. C. Loh, "Familial nonmedullary thyroid carcinoma: a meta-review of case series," Thyroid, vol. 7, no. 1, pp. 107113, 1997.

[28] F. Leprat, F. Bonichon, M. Guyot et al., "Familial nonmedullary thyroid carcinoma: pathology review in 27 affected cases from 13 French families," Clinical Endocrinology, vol. 50, no. 5, pp. 589-594, 1999.

[29] G. Lupoli, G. Vitale, M. Caraglia et al., "Familial papillary thyroid microcarcinoma: a new clinical entity," Lancet, vol. 353, no. 9153, pp. 637-639, 1999.

[30] E. L. Maxwell, F. T. Hall, and J. L. Freeman, "Familial nonmedullary thyroid cancer: a matched-case control study," Laryngoscope, vol. 114, no. 12, pp. 2182-2186, 2004.

[31] S. Uchino, S. Noguchi, H. Kawamoto et al., "Familial nonmedullary thyroid carcinoma characterized by multifocality and a high recurrence rate in a large study population," World Journal of Surgery, vol. 26, no. 8, pp. 897-902, 2002.

[32] Y. Ito, K. Kakudo, M. Hirokawa et al., "Biological behavior and prognosis of familial papillary thyroid carcinoma," Surgery, vol. 145, no. 1, pp. 100-105, 2009.

[33] Y. Ito, T. Uruno, K. Nakano et al., "An observation trial without surgical treatment in patients with papillary microcarcinoma of the thyroid," Thyroid, vol. 13, no. 4, pp. 381387, 2003. 
[34] Y. Ito, C. Tomoda, T. Uruno et al., "Papillary microcarcinoma of the thyroid: how should it be treated?" World Journal of Surgery, vol. 28, no. 11, pp. 1115-1121, 2004.

[35] Y. Ito and A. Miyauchi, "A therapeutic strategy for incidentally detected papillary microcarcinoma of the thyroid," Nature Clinical Practice Endocrinology and Metabolism, vol. 3, no. 3, pp. 240-248, 2007.

[36] Y. Ito, A. Miyauchi, H. Inoue et al., "An observational trial for papillary thyroid microcarcinoma in Japanese patients," World Journal of Surgery, vol. 34, no. 1, pp. 28-35, 2010.

[37] I. Sugitani, K. Toda, K. Yamada, N. Yamamoto, M. Ikenaga, and Y. Fujimoto, "Three distinctly different kinds of papillary thyroid microcarcinoma should be recognized: our treatment strategies and outcomes," World Journal of Surgery, vol. 34, no. 6, pp. 1222-1231, 2010.

[38] H. R. Harach, K. O. Franssila, and V. M. Wasenius, "Occult papillary carcinoma of the thyroid. A 'normal' finding in Finland. A systematic autopsy study," Cancer, vol. 56, no. 3, pp. 531-538, 1985.

[39] F. H. Fukunaga and R. Yatani, "Geographic pathology of occult thyroid carcinomas," Cancer, vol. 36, no. 3, pp. 10951099, 1975.

[40] S. E. Thorvaldsson, H. Tulinius, J. Bjornsson, and O. Bjarnason, "Latent thyroid carcinoma in Iceland at autopsy," Pathology Research and Practice, vol. 188, no. 6, pp. 747-750, 1992.

[41] K. Takebe, M. Date, Y. Yamamoto et al., "Mass screening for thyroid cancer with ultrasonography," KARKINOS, vol. 7, no. 4, pp. 309-317, 1994 (Japanese).

[42] Y. Ito, T. Higashiyama, Y. Takamura et al., "Risk factors for recurrence to the lymph node in papillary thyroid carcinoma patients without preoperatively detectable lateral node metastasis: validity of prophylactic modified radical neck dissection," World Journal of Surgery, vol. 31, no. 11, pp. 2085-2091, 2007.

[43] I. Sugitani, Y. Fujimoto, K. Yamada, and N. Yamamoto, "Prospective outcomes of selective lymph node dissection for papillary thyroid carcinoma based on preoperative ultrasonography," World Journal of Surgery, vol. 32, no. 11, pp. 2494-2502, 2008.

[44] Y. Ito, H. Masuoka, M. Fukushima et al., "Excellent prognosis of patients with solitary T1N0M0 papillary thyroid carcinoma who underwent thyroidectomy and elective lymph node dissection without radioiodine therapy," World Journal of Surgery, vol. 34, no. 6, pp. 1285-1290, 2010.

[45] Y. Ito, C. Tomoda, T. Uruno et al., "Preoperative ultrasonographic examination for lymph node metastasis: usefulness when designing lymph node dissection for papillary microcarcinoma of the thyroid," World Journal of Surgery, vol. 28, no. 5, pp. 498-501, 2004.

[46] Y. Ito, C. Tomoda, T. Uruno et al., "Ultrasonographically and anatomopathologically detectable node metastases in the lateral compartment as indicators of worse relapse-free survival in patients with papillary thyroid carcinoma," World Journal of Surgery, vol. 29, no. 7, pp. 917-920, 2005.

[47] Y. Ito, A. Miyauchi, T. Jikuzono et al., "Risk factors contributing to a poor prognosis of papillary thyroid carcinoma: validity of UICC/AJCC TNM classification and stage grouping," World Journal of Surgery, vol. 31, no. 4, pp. 838-848, 2007.

[48] Y. Ito and A. Miyauchi, "Lateral and mediastinal lymph node dissection in differentiated thyroid carcinoma: indications, benefits, and risks," World Journal of Surgery, vol. 31, no. 5, pp. 905-915, 2007.
[49] Y. Ito and A. Miyauchi, "Lateral lymph node dissection guided by preoperative and intraoperative findings in differentiated thyroid carcinoma," World Journal of Surgery, vol. 32, no. 5, pp. 729-739, 2008.

[50] Y. Ito, M. Fukushima, C. Tomoda et al., "Prognosis of patients with papillary thyroid carcinoma having clinically apparent metastasis to the lateral compartment," Endocrine Journal, vol. 56, no. 6, pp. 759-766, 2009.

[51] Y. Ito, M. Hirokawa, T. Jikuzono et al., "Extranodal tumor extension to adjacent organs predicts a worse cause-specific survival in patients with papillary thyroid carcinoma," World Journal of Surgery, vol. 31, no. 6, pp. 1194-1201, 2007.

[52] F. Pacini, F. Cetani, P. Miccoli et al., "Outcome of 309 patients with metastatic differentiated thyroid carcinoma treated with radioiodine," World Journal of Surgery, vol. 18, no. 4, pp. 600604, 1994.

[53] M. Shoup, A. Stojadinovic, A. Nissan et al., "Prognostic indicators of outcomes in patients with distant metastases from differentiated thyroid carcinoma," Journal of the American College of Surgeons, vol. 197, no. 2, pp. 191-197, 2003.

[54] M. Haq and C. Harmer, "Differentiated thyroid carcinoma with distant metastases at presentation: prognostic factors and outcome," Clinical Endocrinology, vol. 63, no. 1, pp. 8793, 2005.

[55] Y. Orita, I. Sugitani, M. Matsuura et al., "Prognostic factors and the therapeutic strategy for patients with bone metastasis from differentiated thyroid carcinoma," Surgery, vol. 147, no. 3, pp. 424-431, 2010.

[56] Y. Ito, H. Masuoka, M. Fukushima et al., "Prognosis and prognostic factors of patients with papillary carcinoma showing distant metastasis at surgery (M1 patients) in Japan," Endocrine Journal, vol. 57, no. 6, pp. 523-531, 2010.

[57] Y. Ito, C. Tomoda, T. Uruno et al., "Minimal extrathyroid extension does not affect the relapse-free survival of patients with papillary thyroid carcinoma measuring $4 \mathrm{~cm}$ or less over the age of 45 years," Surgery Today, vol. 36, no. 1, pp. 12-18, 2006.

[58] Y. Ito, C. Tomoda, T. Uruno et al., "Prognostic significance of extrathyroid extension of papillary thyroid carcinoma: massive but not minimal extension affects the relapse-free survival," World Journal of Surgery, vol. 30, no. 5, pp. 780786, 2006.

[59] M. Fukushima, Y. Ito, M. Hirokawa, A. Miya, K. Shimizu, and A. Miyauchi, "Prognostic impact of extrathyroid extension and clinical lymph node metastasis in papillary thyroid carcinoma depend on carcinoma size," World Journal of Surgery, vol. 34, no. 12, pp. 3007-3014, 2010.

[60] K. Asanuma, R. Kusama, M. Maruyama, M. Fujimori, and J. Amano, "Macroscopic extranodal invasion is a risk factor for tumor recurrence in papillary thyroid cancer," Cancer Letters, vol. 164, no. 1, pp. 85-89, 2001.

[61] H. Yamashita, S. Noguchi, N. Murakami, H. Kawamoto, and S. Watanabe, "Extracapsular invasion of lymph node metastasis is an indicator of distant metastasis and poor prognosis in patients with thyroid papillary carcinoma," Cancer, vol. 80, no. 12, pp. 2268-2272, 1997.

[62] J. R. Spires, K. T. Robbins, M. A. Luna, and R. M. Byers, "Metastatic papillary carcinoma of the thyroid: the significance of extranodal extension," Head and Neck, vol. 11, no. 3, pp. 242-246, 1989.

[63] I. Macdonald, G. L. O'Hara, and R. A. Weber, "Carcinoma of the thyroid gland: a review of 106 cases," California Medicine, vol. 86, no. 1, pp. 16-19, 1957. 
[64] M. Noguchi, H. Yamada, and N. Ohta, "Regional lymph node metastases in well-differentiated thyroid carcinoma," International Surgery, vol. 72, no. 2, pp. 100-103, 1987.

[65] S. Ahuja, H. Ernst, and K. Lenz, "Papillary thyroid carcinoma: occurrence and types of lymph node metastases," Journal of Endocrinological Investigation, vol. 14, no. 7, pp. 543-549, 1991.

[66] Y. Ito, M. Hirokawa, T. Uruno et al., "Prevalence and biological behaviour of variants of papillary thyroid carcinoma: experience at a single institute," Pathology, vol. 40, no. 6, pp. 617-622, 2008.

[67] H. Y. Chang, J. D. Lin, S. C. Chou, T. C. Chao, and C. Hsueh, "Clinical presentations and outcomes of surgical treatment of follicular variant of the papillary thyroid carcinomas," Japanese Journal of Clinical Oncology, vol. 36, no. 11, pp. 688693, 2006.

[68] J. Liu, B. Singh, G. Tallini et al., "Follicular variant of papillary thyroid carcinoma: a clinicopathologic study of a problematic entity," Cancer, vol. 107, no. 6, pp. 1255-1264, 2006.

[69] P. Hagag, N. Hod, E. Kummer, M. Cohenpour, T. Horne, and M. Weiss, "Follicular variant of papillary thyroid carcinoma: clinical-pathological characterization and long-term followup," Cancer Journal, vol. 12, no. 4, pp. 275-282, 2006.

[70] T. L. Johnson, R. V. Lloyd, N. W. Thompson, W. H. Beierwaltes, and J. C. Sisson, "Prognostic implications of the tall cell variant of papillary thyroid carcinoma," American Journal of Surgical Pathology, vol. 12, no. 1, pp. 22-27, 1988.

[71] A. M. Egea, J. M. R. Gonzalez, J. S. Perez, T. S. Cogollos, and P. Parrilla Paricio, "Prognostic value of the tall cell variety of papillary cancer of the thyroid," European Journal of Surgical Oncology, vol. 19, no. 6, pp. 517-521, 1993.

[72] J. J. Michels, M. Jacques, M. Henry-Amar, and S. Bardet, "Prevalence and prognostic significance of tall cell variant of papillary thyroid carcinoma," Human Pathology, vol. 38, no. 2, pp. 212-219, 2007.

[73] Y. Ito, M. Hirokawa, M. Fukushima et al., "Prevalence and prognostic significance of poor differentiation and tall cell variant in papillary carcinoma in Japan," World Journal of Surgery, vol. 32, no. 7, pp. 1535-1543, 2008.

[74] M. Urano, M. Abe, M. Kuroda et al., "Warthin-like tumor variant of papillary thyroid carcinoma: case report and literature review," Pathology International, vol. 51, no. 9, pp. 707-712, 2001.

[75] Z. W. Baloch and V. A. LiVolsi, "Warthin-like papillary carcinoma of the thyroid," Archives of Pathology and Laboratory Medicine, vol. 124, no. 8, pp. 1192-1195, 2000.

[76] M. Ludvíková, A. Ryška, M. Korabečná, M. Rydlová, and M. Michal, "Oncocytic papillary carcinoma with lymphoid stroma (Warthin-like tumour) of the thyroid: a distinct entity with favourable prognosis," Histopathology, vol. 39, no. 1, pp. 17-24, 2001.

[77] S. M. Chow, J. K. C. Chan, S. C. K. Law et al., "Diffuse sclerosing variant of papillary thyroid carcinoma-clinical features and outcome," European Journal of Surgical Oncology, vol. 29, no. 5, pp. 446-449, 2003.

[78] A. K. Lam and C. Y. Lo, "Diffuse sclerosing variant of papillary carcinoma of the thyroid: a 35-year comparative study at a single institution," Annals of Surgical Oncology, vol. 13, no. 2, pp. 176-181, 2006.

[79] L. Falvo, L. Giacomelli, V. D’Andrea, A. Marzullo, G. Guerriero, and E. De Antoni, "Prognostic importance of sclerosing variant in papillary thyroid carcinoma," American Surgeon, vol. 72, no. 5, pp. 438-444, 2006.
[80] M. Fukushima, Y. Ito, M. Hirokawa, H. Akasu, K. Shimizu, and A. Miyauchi, "Clinicopathologic characteristics and prognosis of diffuse sclerosing variant of papillary thyroid carcinoma in Japan: an 18-year experience at a single institution," World Journal of Surgery, vol. 33, no. 5, pp. 958962, 2009.

[81] A. Lugli, L. M. Terracciano, M. Oberholzer, L. Bubendorf, and L. Tornillo, "Macrofollicular variant of papillary carcinoma of the thyroid: a histologic, cytologic, and immunohistochemical study of 3 cases and review of the literature," Archives of Pathology and Laboratory Medicine, vol. 128, no. 1, pp. 54-58, 2004.

[82] J. Albores-Saavedra, E. Gould, C. Vardaman, and F. Vuitch, "The macrofollicular variant of papillary thyroid carcinoma: a study of 17 cases," Human Pathology, vol. 22, no. 12, pp. 1195-1205, 1991.

[83] M. Fukushima, Y. Ito, M. Hirokawa et al., "Macrofollicular variant of papillary thyroid carcinoma: its clinicopathological features and long-term prognosis," Endocrine Journal, vol. 56, no. 3, pp. 503-508, 2009.

[84] K. M. Dalal, D. Moraitis, C. Iwamoto, A. R. Shaha, S. G. Patel, and R. A. Ghossein, "Clinical curiosity: cribriform-morular variant of papillary thyroid carcinoma," Head and Neck, vol. 28, no. 5, pp. 471-476, 2006.

[85] C. Tomoda, A. Miyauchi, T. Uruno et al., "Cribriformmorular variant of papillary thyroid carcinoma: clue to early detection of familial adenomatous polyposis-associated colon cancer," World Journal of Surgery, vol. 28, no. 9, pp. 886-889, 2004.

[86] Y. Ito, M. Hirokawa, T. Uruno et al., "Biological behavior and prognosis of encapsulated papillary carcinoma of the thyroid: experience of a Japanese hospital for thyroid care," World Journal of Surgery, vol. 32, no. 8, pp. 1789-1794, 2008.

[87] Z. W. Baloch, K. Shafique, M. Flannagan, and V. A. LiVolsi, "Encapsulated classic and follicular variants of papillary thyroid carcinoma: comparative clinicopathologic study," Endocrine Practice, vol. 16, no. 6, pp. 952-959, 2010.

[88] I. Sugitani, K. Toda, N. Yamamoto, A. Sakamoto, and Y. Fujimoto, "Re-evaluation of histopathological factors affecting prognosis of differentiated thyroid carcinoma in an iodinesufficient country," World Journal of Surgery, vol. 34, no. 6, pp. 1265-1273, 2010.

[89] M. Volante, I. Rapa, and M. Papotti, "Poorly differentiated thyroid carcinoma: diagnostic features and controversial issues," Endocrine Pathology, vol. 19, no. 3, pp. 150-155, 2008.

[90] D. Hiltzik, D. L. Carlson, R. M. Tuttle et al., "Poorly differentiated thyroid carcinomas defined on the basis of mitosis and necrosis: a clinicopathologic study of 58 patients," Cancer, vol. 106, no. 6, pp. 1286-1295, 2006.

[91] E. A. Ha, E. Ismail, M. Abbas, and K. Ouf, "MIB-1 index, S-phase fraction, mitotic figure count, and SBR histologic grading in invasive breast carcinoma: a comparative study," Breast Journal, vol. 7, no. 2, pp. 106-110, 2001.

[92] P. Kurki, M. Vanderlaan, and F. Dolbeare, "Expression of proliferating cell nuclear antigen (PCNA)/cyclin during the cell cycle," Experimental Cell Research, vol. 166, no. 1, pp. 209-219, 1986

[93] G. Cattoretti, M. H. G. Becker, G. Key et al., "Monoclonal antibodies against recombinant parts of the Ki-67 antigen (MIB 1 and MIB 3) detect proliferating cells in microwaveprocessed formalin-fixed paraffin sections," Journal of Pathology, vol. 168, no. 4, pp. 357-363, 1992.

[94] R. P. Sullivan, G. Mortimer, and I. O. Muircheartaigh, "Cell proliferation in breast tumours: analysis of histological 
parameters Ki67 and PCNA expression," Irish Journal of Medical Science, vol. 162, no. 9, pp. 343-347, 1993.

[95] J. W. Hoyt, A. M. Gown, D. K. Kim, and M. S. Berger, "Analysis of proliferative grade in glial neoplasms using antibodies to the Ki-67 defined antigen and PCNA in formalin fixed, deparaffinized tissues," Journal of NeuroOncology, vol. 24, no. 2, pp. 163-169, 1995.

[96] A. Sofiadis, E. Tani, T. Foukakis et al., "Diagnostic and prognostic potential of MIB-1 proliferation index in thyroid fine needle aspiration biopsy," International Journal of Oncology, vol. 35, no. 2, pp. 369-374, 2009.

[97] Y. Ito, A. Miyauchi, K. Kakudo, M. Hirokawa, K. Kobayashi, and A. Miya, "Prognostic significance of Ki-67 labeling index in papillary thyroid carcinoma," World Journal of Surgery, vol. 34, no. 12, pp. 3015-3021, 2010.

[98] K. E. Mercer and C. A. Pritchard, "Raf proteins and cancer: B-Raf is identified as a mutational target," Biochimica et Biophysica Acta, vol. 1653, no. 1, pp. 25-40, 2003.

[99] S. Torii, K. Nakayama, T. Yamamoto, and E. Nishida, "Regulatory mechanisms and function of ERK MAP kinases," Journal of Biochemistry, vol. 136, no. 5, pp. 557-561, 2004.

[100] M. Kohno and J. Pouyssegur, "Targeting the ERK signaling pathway in cancer therapy," Annals of Medicine, vol. 38, no. 3, pp. 200-211, 2006.

[101] M. J. Garnett and R. Marais, "Guilty as charged: B-RAF is a human oncogene," Cancer Cell, vol. 6, no. 4, pp. 313-319, 2004.

[102] K. H. Kim, D. W. Kang, S. H. Kim, I. O. Seong, and D. Y. Kang, "Mutations of the BRAF gene in papillary thyroid carcinoma in a Korean population," Yonsei Medical Journal, vol. 45, no. 5, pp. 818-821, 2004.

[103] T. Y. Kim, W. B. Kim, Y. S. Rhee et al., "The BRAF mutation is useful for prediction of clinical recurrence in low-risk patients with conventional papillary thyroid carcinoma," Clinical Endocrinology, vol. 65, no. 3, pp. 364-368, 2006.

[104] T. Fukushima, S. Suzuki, M. Mashiko et al., "BRAF mutations in papillary carcinomas of the thyroid," Oncogene, vol. 22, no. 41, pp. 6455-6457, 2003.

[105] H. Namba, M. Nakashima, T. Hayashi et al., "Clinical implication of hot spot BRAF mutation, V599E, in papillary thyroid cancers," Journal of Clinical Endocrinology and Metabolism, vol. 88, no. 9, pp. 4393-4397, 2003.

[106] A. J. Adeniran, Z. Zhu, M. Gandhi et al., "Correlation between genetic alterations and microscopic features, clinical manifestations, and prognostic characteristics of thyroid papillary carcinomas," American Journal of Surgical Pathology, vol. 30, no. 2, pp. 216-222, 2006.

[107] L. Fugazzola, E. Peuxeddu, N. Avenia et al., "Correlation between B-RAFV600E mutation and clinicopathologic parameters in papillary thyroid carcinoma: data from a multicentric Italia study and review of the literature," Endocrine Related Cancer, vol. 13, no. 2, pp. 455-463, 2006.

[108] E. Kebebew, J. Weng, J. Bauer et al., "The prevalence and prognostic value of BRAF mutation in thyroid cancer," Annals of Surgery, vol. 246, no. 3, pp. 466-470, 2007.

[109] M. Xing, W. H. Westra, R. P. Tufano et al., "BRAF mutation predicts a poorer clinical prognosis for papillary thyroid cancer," Journal of Clinical Endocrinology and Metabolism, vol. 90, no. 12, pp. 6373-6379, 2005.

[110] I. Yasuhiro, H. Yoshida, R. Maruo et al., "BRAF mutation in papillary thyroid carcinoma in a Japanese population: its lack of correlation with high-risk clinicopathological features and disease-free survival of patients," Endocrine Journal, vol. 56, no. 1, pp. 89-97, 2009.
[111] C. Lupi, R. Giannini, C. Ugolini et al., "Extensive clinical experience: association of BRAF V600E mutation with poor clinicopathological outcomes in 500 consecutive cases of papillary thyroid carcinoma," Journal of Clinical Endocrinology and Metabolism, vol. 92, no. 11, pp. 4085-4090, 2007.

[112] M. N. Nikiforova, E. T. Kimura, M. Gandhi et al., "BRAF mutations in thyroid tumors are restricted to papillary carcinomas and anaplastic or poorly differentiated carcinomas arising from papillary carcinomas," Journal of Clinical Endocrinology and Metabolism, vol. 88, no. 11, pp. 53995404, 2003.

[113] Y. Ito, M. Hirokawa, T. Higashiyama et al., "Prognosis and prognostic factors of follicular carcinoma in Japan: Importance of postoperative pathological examination," World Journal of Surgery, vol. 31, no. 7, pp. 1417-1424, 2007.

[114] H. W. Mueller-Gaertner, H. T. Brzac, and W. Rehpenning, "Prognostic indices for tumor relapse and tumor mortality in follicular thyroid carcinoma," Cancer, vol. 67, no. 7, pp. 1903-1911, 1991.

[115] W. J. Simpson, S. E. McKinney, J. S. Carruthers, M. K. Gospodarowicz, S. B. Sutcliffe, and T. Panzarella, "Papillary and follicular thyroid cancer," American Journal of Medicine, vol. 83, no. 3, pp. 479-488, 1987.

[116] A. R. Shaha, T. R. Loree, J. P. Shah et al., "Prognostic factors and risk group analysis in follicular carcinoma of the thyroid," Surgery, vol. 118, no. 6, pp. 1131-1138, 1995.

[117] G. Crile Jr., K. I. Pontius, and W. A. Hawk, "Factors influencing the survival of patients with follicular carcinoma of the thyroid gland," Surgery Gynecology and Obstetrics, vol. 160, no. 5, pp. 409-413, 1985.

[118] H. Joensuu, P. J. Klemi, R. Paul, and J. Tuominen, "Survival and prognostic factors in thyroid carcinoma," Acta Radiologica Oncology, vol. 25, no. 3, pp. 167-170, 1986.

[119] J. Zidan, S. Kassem, and A. Kuten, "Follicular carcinoma of the thyroid gland: Prognostic factors, treatment, and survival," American Journal of Clinical Oncology, vol. 23, no. 1, pp. 1-5, 2000.

[120] J. Witte, P. E. Goretzki, J. Dieken, D. Simon, and H. D. Röher, "Importance of lymph node metastases in follicular thyroid cancer," World Journal of Surgery, vol. 26, no. 8, pp. 10171022, 2002.

[121] N. Besic, J. Zgajnar, M. Hocevar, and S. Frkovic-Grazio, "Is patient's age a prognostic factor for follicular thyroid carcinoma in the TNM classification system?" Thyroid, vol. 15, no. 5, pp. 439-448, 2005.

[122] S. M. Chow, S. C. K. Law, W. M. Mendenhall et al., "Follicular thyroid carcinoma: prognostic factors and the role of radioiodine," Cancer, vol. 95, no. 3, pp. 488-498, 2002.

[123] Y. Ito, M. Fukushima, T. Yabuta et al., "Prevalence and prognosis of familial follicular thyroid carcinoma," Endocrine Journal, vol. 55, no. 5, pp. 847-852, 2008.

[124] C. Y. Lo, W. F. Chan, K. Y. Lam, and K. Y. Wan, "Follicular thyroid carcinoma: the role of histology and staging systems in predicting survival," Annals of Surgery, vol. 242, no. 5, pp. 708-715, 2005.

[125] R. Asari, O. Koperek, C. Scheuba et al., "Follicular thyroid carcinoma in an iodine-replete endemic goiter region: a prospectively collected, retrospectively analyzed clinical trial," Annals of Surgery, vol. 249, no. 6, pp. 1023-1031, 2009.

[126] E. Yutan and O. H. Clark, "Hurthle cell carcinoma," Current Treatment Options in Oncology, vol. 2, no. 4, pp. 331-335, 2001. 
[127] Y. Kushchayeva, Q. Y. Duh, E. Kebebew, and O. H. Clark, "Prognostic indications for Hürthle cell cancer," World Journal of Surgery, vol. 28, no. 12, pp. 1266-1270, 2004.

[128] C. S. Grant, I. D. Hay, J. J. Ryan, E. J. Bergstralh, L. M. Rainwater, and J. R. Goellner, "Diagnostic and prognostic utility of flow cytometric DNA measurements in follicular thyroid tumors," World Journal of Surgery, vol. 14, no. 3, pp. 283-290, 1990.

[129] P. L. Haigh and D. R. Urbach, "The treatment and prognosis of Hürthle cell follicular thyroid carcinoma compared with its non-Hürthle cell counterpart," Surgery, vol. 138, no. 6, pp. 1152-1158, 2005.

[130] N. Besic, M. Auersperg, and R. Golouh, "Prognostic factors in follicular carcinoma of the thyroid-a multivariate survival analysis," European Journal of Surgical Oncology, vol. 25, no. 6, pp. 599-605, 1999.

[131] K. Sugino, K. Ito, T. Mimura, K. Kameyama, H. Iwasaki, and K. Ito, "Hürthle cell tumor of the thyroid: analysis of 188 patients," World Journal of Surgery, vol. 25, no. 9, pp. 11601163, 2001. 


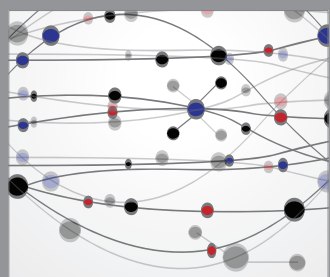

The Scientific World Journal
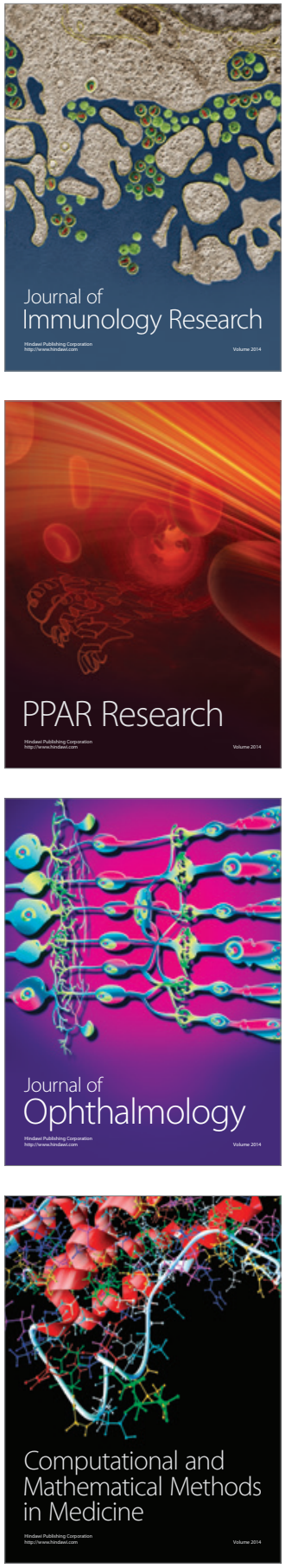

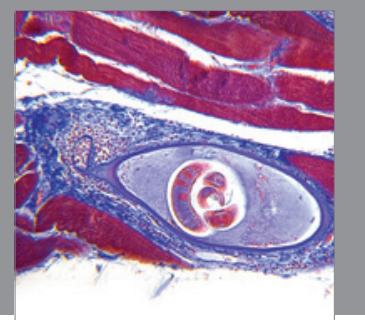

Gastroenterology

Research and Practice
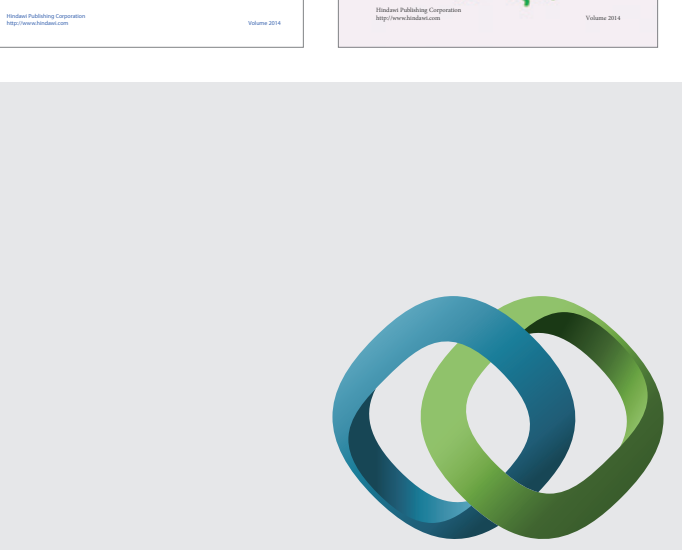

\section{Hindawi}

Submit your manuscripts at

http://www.hindawi.com
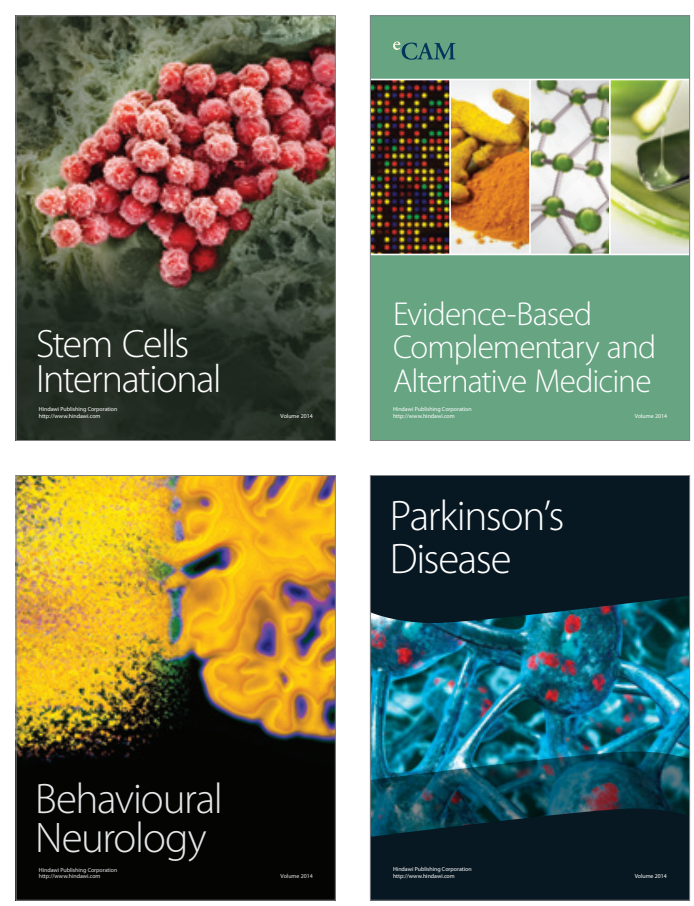

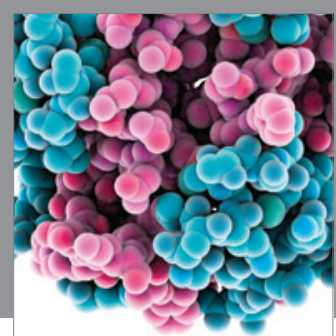

Journal of
Diabetes Research

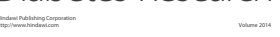

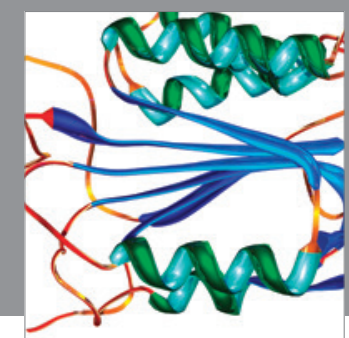

Disease Markers
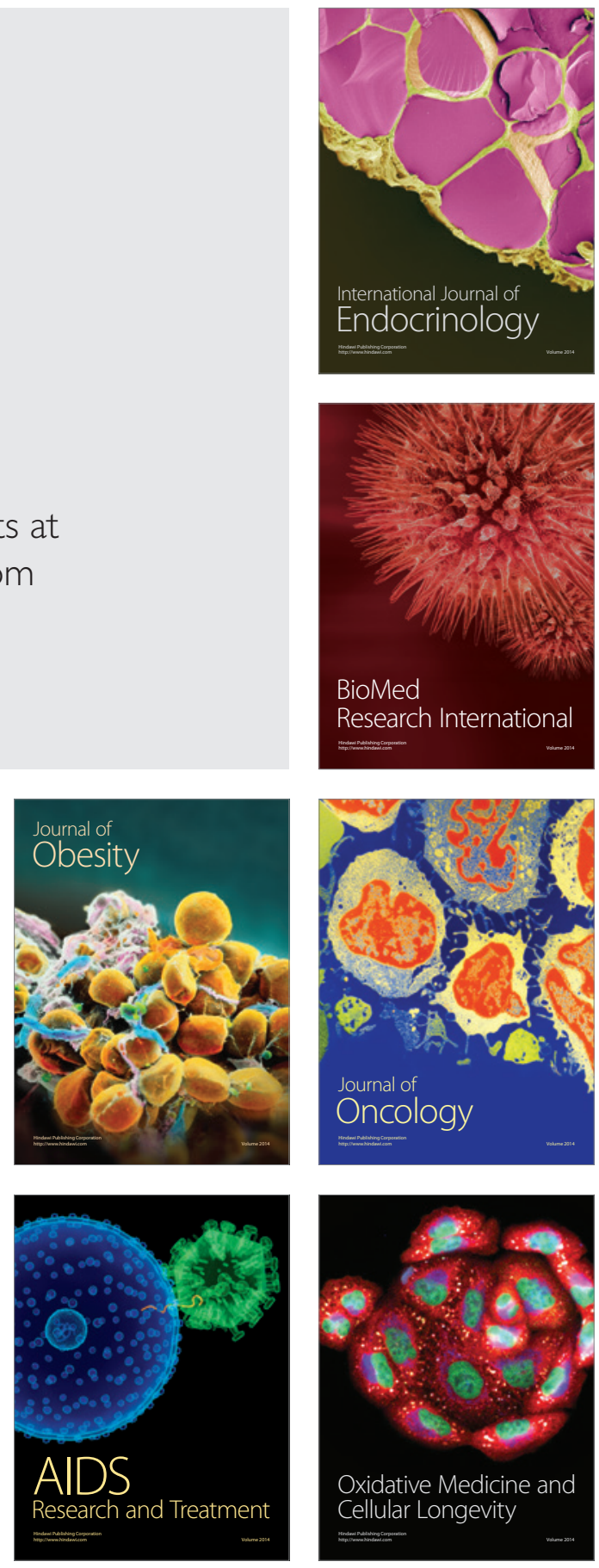